\title{
Fabrication and Characterization of Friction Stir- Processed Mg-Zn-Ca Biomaterials Strengthened with MgO Particles
}

\section{Zhen Liu}

Tianjin University of Technology

\section{Yangchuan Cai}

Tianjin University of Technology

Jie Chen

Shandong University

Jian Han ( $\square$ hj_tjut@vip.126.com )

Tianjin University of Technology

\section{Zhiyong Mao}

Tianjin University of Technology

\section{Minfang Chen}

Tianjin University of Technology

\section{Research Article}

Keywords: Magnesium matrix composite, Friction stir processing, Microstructure, Mechanical property, Corrosion resistance, Grain misorientation

Posted Date: May 11th, 2021

DOl: https://doi.org/10.21203/rs.3.rs-502331/v1

License: (c) (i) This work is licensed under a Creative Commons Attribution 4.0 International License. Read Full License

Version of Record: A version of this preprint was published at The International Journal of Advanced Manufacturing Technology on August 3rd, 2021. See the published version at https://doi.org/10.1007/s00170-021-07814-9. 


\section{Fabrication and characterization of friction stir-processed $\mathrm{Mg}-\mathrm{Zn}-\mathrm{Ca}$}

\section{biomaterials strengthened with MgO particles}

Zhen Liu ${ }^{\mathrm{a}, \#}$, Yangchuan Cai ${ }^{\mathrm{a}, \#}$, Jie Chen ${ }^{\mathrm{b}}$, Jian Han ${ }^{\mathrm{a}, *}$, Zhiyong Mao ${ }^{\mathrm{a}, \mathrm{c}}$, Minfang

$$
\text { Chen }^{\mathrm{a}, \mathrm{c}, \mathrm{d}, * *}
$$

${ }^{a}$ Faculty of Materials Science and Engineering, Tianjin University of Technology, Tianjin 300384,

P.R. China

${ }^{b}$ Faculty of Materials Science and Engineering, Shandong University, Jinan 250061, P.R. China

${ }^{c}$ Key Laboratory of Display Materials and Photoelectric Devices, Tianjin University of Technology,

Ministry of Education, Beijing 100816, P.R. China

${ }^{d}$ Tianjin Key Lab for Photoelectric Materials \& Devices, Tianjin 300384, P.R. China

${ }^{\#}$ Both authors contribute equally to this work.

*Corresponding author: Jian Han*, Minfang Chen**

Email: hj_tjut@vip.126.com, Tel: +86-13564797997

Email: mfchentj@126.com, Tel: +86-22-60215845

Address: School of Materials Science and Engineering, Tianjin University of Technology, No. 391, Binshui West Road, Xiqing District, Tianjin 300384, P.R. China.

ABSTRACT: Magnesium alloy composites play an important role in biomaterials field. In this study, a novel $\mathrm{Mg}-\mathrm{Zn}-\mathrm{Ca}$ matrix composite was reinforced by adding $1.0 \mathrm{wt} . \%$ $\mathrm{MgO}$ nanoparticles via the high shear casting process. Hereafter, friction stir processing 
(FSP) was used to achieve a good dispersion of $\mathrm{MgO}$ particles and improve the mechanical properties of the composites. After the preparation of the novel composite materials, varied characterization and performance test methods have been selected for comparison. The results illustrate that through FSP, the corresponding microstructure and properties of as-cast $\mathrm{MgO} / \mathrm{Mg}-\mathrm{Zn}-\mathrm{Ca}$ composites were significantly modified, and the best combination of the key parameters is $1200 \mathrm{rpm}$ and $60 \mathrm{~mm} / \mathrm{min}$ for rotational velocity and traveling speed, respectively. After the optimized FSP treatment, the grains size in FSP-processed composites were refined by $42 \%$, to reach $1.04 \mu \mathrm{m}$. Due to the grain refinement and the redistribution of $\mathrm{MgO}$ particles, the hardness of the FSPprocessed $\mathrm{MgO} / \mathrm{Mg}-\mathrm{Zn}-\mathrm{Ca}$ composites were increased by $40 \%$, to reach $101.2 \mathrm{HV}$. Further, it displayed excellent corrosion resistance as well as strength. Compared to the strengthening through grain refinement, the particle strengthening is more dominant based on the study. And meanwhile, the modified grains and added $\mathrm{MgO}$ particles are beneficial to the properties of the nugget zones.

Keywords: Magnesium matrix composite, Friction stir processing, Microstructure, Mechanical property, Corrosion resistance, Grain misorientation

\section{Introduction}

Magnesium (Mg) alloys have become one of the hot topics in many fields due to their adjustable mechanical behavior and corrosion resistance [1, 2]. To further expand the application of $\mathrm{Mg}$ alloys, $\mathrm{Mg}$ metal matrix composites (Mg-MMCs) are being 
developed step by step, compared to conventional Mg alloys, Mg-MMCs have superior properties, such as higher strength, hardness and corrosion resistance [3, 4]. In recent years, the reinforced Mg-MMCs with ceramic particles, for instance, hydroxyapatite (HA) or $\beta$-tricalcium phosphate $(\beta$-TCP), were found to significantly improve performances for these composites. In the work of Jaiswal et al. [5], it has improved the corrosion resistance, bioactivity, and mechanical strength of degradable $\mathrm{Mg}$ alloys through synthesizing heat treatment of hydroxyapatite-reinforced $\mathrm{Mg}-3 \mathrm{wt} \% \mathrm{Zn}$-based composite materials. Liu et al. [6] have adopted the new melt shearing technique integrating with high pressure die casting to uniformly add nano-scale tricalcium phosphate $(\beta-\mathrm{TCP})$ to $\mathrm{Mg}-3 \mathrm{Zn}-\mathrm{Ca}$ composite materials, which have improved the hardness and tensile strength.

It is well accepted that $\mathrm{ZrO}_{2}, \mathrm{TiO}_{2}$ and $\mathrm{MgO}$ have good chemical stability, enabling them the suitable strengthening phases for the Mg matrix, as Lin et al. [7] have studied. Goh et al. [8] have produced the $\mathrm{MgO} / \mathrm{Mg}$ composites with improved strength and hardness. As a strengthening phase, $\mathrm{MgO}$ has not only improve the mechanical behavior of the material, but also the effect of increased corrosion resistance. Khalajabadi et al. [9] have used the powder metallurgy method to prepare $\mathrm{Mg} / \mathrm{HA} / \mathrm{MgO}$ nanocomposites, and the results show that with more $\mathrm{MgO}$, the corrosion resistance turns better and better, which is due to thicker product film, and subsequent reduction of pitting corrosion. Lei et al. [10] have prepared $\mathrm{MgO} / \mathrm{Mg}-\mathrm{Zn}$ composites and found that the addition of $\mathrm{MgO}$ led to both grain refinement and second phase strengthening, and therefore mechanical properties and corrosion resistance are significantly improved. 
However, Lin et al. [7] have found that irrespective of manufacturing methods, when the $\mathrm{MgO}$ content is about $0.5 \mathrm{wt} . \%$ or more, the phenomenon of agglomeration occurs, influencing negatively the mechanical behavior and corrosion properties of the composites. In this research, the application of severe plastic deformation (SPD) to improve the properties of the $\mathrm{MgO} / \mathrm{Mg}-\mathrm{Zn}-\mathrm{Ca}$ composites has been proposed. SPD has been extensively applied to improve materials' properties, among them, FSP is one of the typical and essential SPD methods[11,12]. Due to the high heat input of FSP, it was confirmed to be effective to optimize the microstructure and properties of Mg-MMCs.

Vandana et al. [13] have incorporated nano-scaled HA into the pure Mg sheets through FSP, and the grains of the obtained composites in the stir zone are found to be refined from the initial size of $2000 \mu \mathrm{m}$ to around $10 \mu \mathrm{m}$. Morisada et al. [14] have dispersed multi-walled carbon nanotubes (MWCNTs) into AZ31 using FSP. It was found that this method can refine the grains, and increase the microhardness by twice. Sahraeinejad et al. [15] have incorporated nano-scaled $\mathrm{B}_{4} \mathrm{C}$ into the matrix of $\mathrm{Al} 5059$, and found that the average microhardness within the stir zone has been increased from $85 \mathrm{HV}$ to a maximum of $170 \mathrm{HV}$. Lee et al. [16] have added $\mathrm{SiO}_{2}$ nanoparticles to AZ61, the average grain size of prepared composite material is in the range of $0.5 \sim 2 \mu \mathrm{m}$, and the hardness of the material is almost twice of the matrix. Asadi et al. [17] have applied FSP to prepare a SiC/AZ91 composite layer, and $5 \mu \mathrm{m} \mathrm{SiC} \mathrm{particles} \mathrm{for} \mathrm{reinforcement}$ and grain refinement. Based on the study, the stirring treatment is beneficial to refine the grains with increasing rotational and traveling speeds, which induces the strengthening. 
Up to the present, a large number of composite materials have been prepared through FSP. However, most studies on performance improvement, focusing on the following points: (1) to rely on FSP to integrate reinforced particles into the metal matrix, (2) with combined actions of added particles as well as FSP, the grains are refined and the performance is improved accordingly. However, few studies have used FSP to improve the microstructure and performance of biomedical composites. In this study, the application of SPD to further improve the properties of the $\mathrm{MgO} / \mathrm{Mg}-\mathrm{Zn}-\mathrm{Ca}$ biomedical composites through optimized powder metallurgy and casting is proposed.

Aiming at the first step of medical application, the properties of the casting composite, especially mechanical properties and corrosion resistance, are necessary to be improved to be fit for implanting the components in the human body. Therefore, the nanoparticle-reinforced $\mathrm{Mg}$ matrix and FSP-ed composite ( $\mathrm{MgO} / \mathrm{Mg}-\mathrm{Zn}-\mathrm{Ca}$ ) have been fabricated and characterized in this study. The $\mathrm{MgO} / \mathrm{Mg}-\mathrm{Zn}-\mathrm{Ca}$ was produced using casting and hot extrusion process, followed by FSP. The traveling speed and rotating velocity were changed accordingly, and the influences on the microstructure, mechanical behaviors and corrosion properties have been investigated to verify the effects of SPD.

\section{Experimental procedure}

The chemical composition of the $\mathrm{MgO} / \mathrm{Mg}-\mathrm{Zn}-\mathrm{Ca}$ composite in this study is listed in Table 1. The $\mathrm{Mg}$ ingot, $\mathrm{Zn}$ ingot and $\mathrm{Mg}$-Ca alloy, were melted in $690 \sim 700{ }^{\circ} \mathrm{C}$ under the protection of the mixed gas, i.e. $\mathrm{SF}_{6}$ and $\mathrm{N}_{2}$. After the $\mathrm{MgO}$ nanoparticles were brought into the molten metal, a high shear rotor-stator mixer was used to stir $\mathrm{MgO}$ 
fully with the molten metal using a stirring velocity of $4000 \mathrm{rpm}$ for $5 \mathrm{~min}$. Then, the metal was cast into a mold at $680{ }^{\circ} \mathrm{C}$ to form ingots with a diameter of $60 \mathrm{~mm}$. After that, the ingot was annealed at $300{ }^{\circ} \mathrm{C}$ for $20 \mathrm{~h}$ to achieve homogenization before final hot extrusion to the size of $1.5 \mathrm{~mm} \times 30 \mathrm{~mm}$ (thickness $\times$ width). The ingots were then divided into billets with a length of $200 \mathrm{~mm}$ via wire-electrode cutting.

\section{Table 1}

Composition of $\mathrm{MgO} / \mathrm{Mg}-\mathrm{Zn}-\mathrm{Ca}$ composite (wt.\%).

\begin{tabular}{cccc}
\hline $\mathrm{Zn}$ & $\mathrm{Ca}$ & $\mathrm{MgO}$ & $\mathrm{Mg}$ \\
\hline 3.0 & 0.2 & 1.0 & Balance \\
\hline
\end{tabular}

The FSP was carried out using HT-JM $16 \times 15 / 2$ gantry friction stir processing machine. Fig. 1a shows the schematic diagram of the manufacturing process. The stirring tool was made of $\mathrm{H} 13$ die steel. The pin has an $8.0 \mathrm{~mm}$ shoulder diameter with a $2.5 \mathrm{~mm}$ tapered pin and a $1.0 \mathrm{~mm}$ length, shown in Fig. 1b. Based on the investigation, a tilt angle of $2.5^{\circ}$ was machined, and the principal axis was rotated in a clockwise direction during the FSP. Furthermore, four combinations of the key parameters (pin rotational and traveling speeds) were selected, as listed in Table 2. 

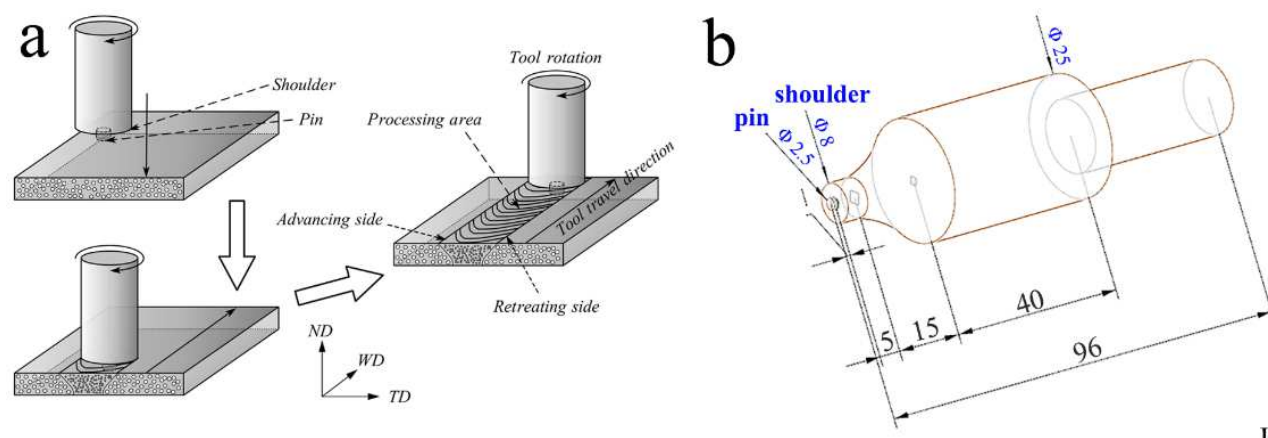

Unit:mm

Fig. 1. (a) Schematic illustration of FSP process (WD-welding direction, ND-normal direction, TD-transverse direction); (b) Design of stirring pin.

\section{Table 2}

Key parameters during FSP.

\begin{tabular}{cccc} 
No. & Rotating velocity, $\omega(\mathrm{r} / \mathrm{min}$ or $\mathrm{rpm})$ & Traveling speed, $v(\mathrm{~mm} / \mathrm{min})$ & $\omega / v$ \\
\hline 1 & 800 & 60 & 13.3 \\
2 & 1000 & 60 & 16.6 \\
3 & 1200 & 60 & 20.0 \\
4 & 1200 & 80 & 15.0
\end{tabular}

The parameters of the FSP, including the stirring tool shape, traveling speed and rotational velocity of this tool, influence the flow of metal. During the FSP, the pressure on the shaft shoulder was kept unchanged. To determine the parameter influence on performance, the heat input has to be taken into account. As for heat input, i.e. $E$, it can be calculated by the following equation (Equation 1):

$$
E=\frac{\pi \omega \mu \mathrm{P}\left(\mathrm{r}_{0}^{2}+\mathrm{r}_{0} \mathrm{r}_{1}+\mathrm{r}_{1}^{2}\right)}{45\left(\mathrm{r}_{0+} \mathrm{r}_{1}\right) \mathrm{v}}
$$


Where, $\mu$ is the constant friction coefficient related to the type and state of materials; $P$ is the shoulder pressure of stirring tool related to the shaft shoulder pressure and material characteristics; $\omega$ is the rotational velocity; $v$ is the traveling speed; $r_{0}$ is the shoulder radius; and $r_{l}$ is the radius of the stirring pin. Since a same stirring tool was used in the FSP, the shape of the tool is fixed. The other parameters during the FSP were kept unchanged except for the ratio of rotational speed and traveling speed. It can be considered $E=R \frac{\omega}{v}\left(R=\frac{\pi \mu P\left(r_{0}^{2}+r_{0} r_{1}+r_{1}^{2}\right)}{45\left(r_{0+} r_{1}\right)}\right.$, which is an unaltered amount). Abbasi et al. [18] have used $\omega / v$ to compare the influence of heat input when studying the mechanical behavior of friction stir welding on different areas of AZ31 magnesium alloy. Therefore, the heat inputs of different FSP processes can be compared by the values of $\omega / \nu$, listed in Table 2 .

The samples for metallographic examinations were sectioned and prepared according to the standard metallography procedures. Then, the samples were electrochemically polished with a solution of $5 \mathrm{ml} \mathrm{10 \%} \mathrm{nitric} \mathrm{acid} \mathrm{and} 45 \mathrm{ml}$ methanol and then etched using a mixed solution of $5 \mathrm{ml}$ deionized water, $2.5 \mathrm{ml}$ glacial acetic acid, $2.75 \mathrm{~g}$ picric acid, and $45 \mathrm{ml}$ anhydrous ethanol. Afterward, the surface morphology and defects were observed by the DSX-HRSU stereomicroscope. The microstructures were examined using Olympus TV0.5XC-3 optical microscope (OM). Image-Pro Plus software was used to analyze the distribution of grain size. Relying on Scanning Electron Microscope (SEM) (Quanta FEG 250), together with its energy dispersive spectrometer (EDS), further microstructure studies were conducted. X-ray diffraction (XRD) was used with an X-ray diffractometer (Rigaku Ultima IV) with a 
scanning speed within $20^{\circ} \sim 80^{\circ}$. The Electron back-scattered diffraction (EBSD) whose brand is Oxford Nordlys Nano was applied for further microstructure analysis of the selected samples. The samples for EBSD were mechanically ground and polished, and further processed using an ion etcher (Leica RES101). The transverse direction-normal direction (TD-ND) surfaces of the sample were then characterized, and the data were analyzed application the software of Channel 5.

Microhardness testing in Vickers was performed along the transverse section of the samples using a $490.3 \mathrm{mN}$ load for a $10 \mathrm{~s}$ dwell time at the intervals of $0.5 \mathrm{~mm}$. From the center area of the weld nugget, each point is spaced at $0.5 \mathrm{~mm}$ horizontal test, and three longitudinal tests are performed at each interval to calculate the standard deviation.

Electrochemical corrosion test was performed at $37{ }^{\circ} \mathrm{C}$ in a Zennium electrochemical workstation, which consists of a glass beaker containing simulated body fluid (SBF) and a standard three-electrode system (saturated calomel electrode (SCE) - reference electrode, sample - working electrode, graphite - control electrode). The surfaces of the tested samples were ground using silicon papers up to 3000\#. After the open circuit voltage was recorded for $30 \mathrm{~min}$, the potential dynamic polarization was performed using a scanning rate of $1 \mathrm{mV} / \mathrm{s}$, and the voltage is from $0.5 \mathrm{~V}$ below the self-corrosion potential to $0.5 \mathrm{~V}$ above the self-corrosion potential.

\section{Results and Discussion}

\subsection{Surface morphology after FSP}

The friction heat that has been generated between the shoulder of the stirring tool 
shaft and the surface of the processed material resulted in plastic deformation in the metal. The materials rotated with the shaft shoulder under pressure, forming the fishscale pattern, as shown in Fig. 2. With the increasing rotational speed of the stirring tool, the rotational number increases, and the processed surface became smoother. As for the traveling speed, the lower traveling speed causes the stirring head to rotate more at the same distance, so the pitch of the fish-scale curve is reduced to form a smooth weld bead. Furthermore, since a high heat input is possible to result in the plastic flow of materials, higher heat input is preferred in the FSP of the $\mathrm{MgO} / \mathrm{Mg}-\mathrm{Zn}-\mathrm{Ca}$ composite if the surface quality can be controlled in good quality.
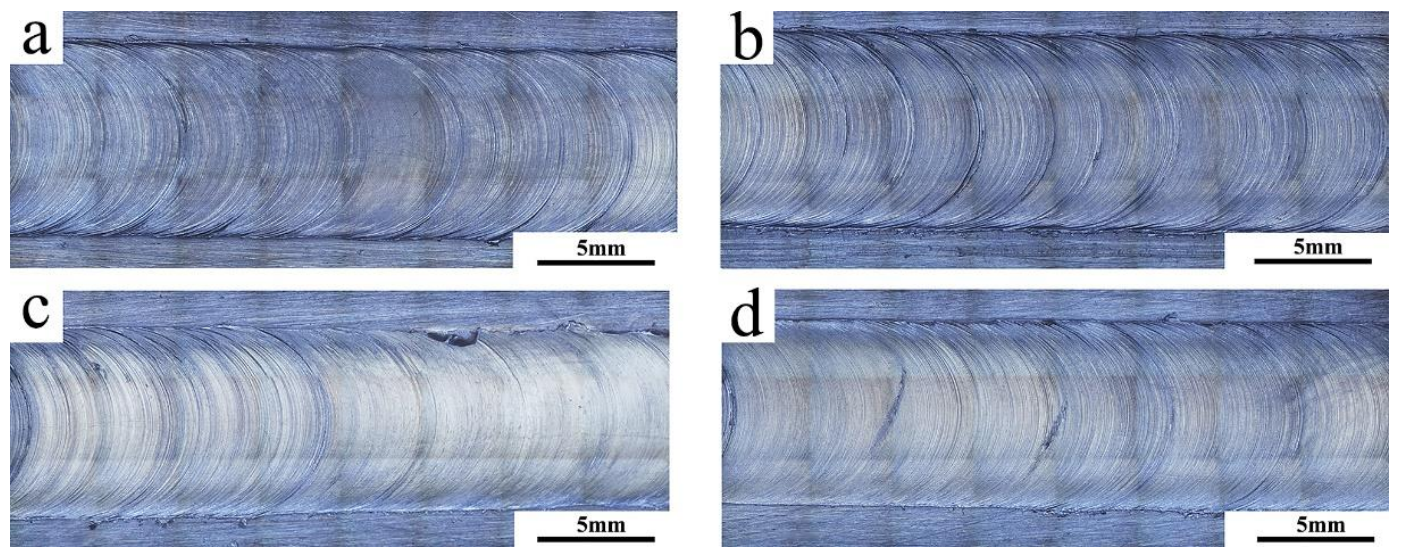

Fig. 2. Macroscopic morphology of FSP samples with different parameters: (a) 800 rpm-60 mm/min, (b) $1000 \mathrm{rpm}-60 \mathrm{~mm} / \mathrm{min}$, (c) $1200 \mathrm{rpm}-60 \mathrm{~mm} / \mathrm{min}$, (d) $1200 \mathrm{rpm}-$ $80 \mathrm{~mm} / \mathrm{min}$.

\subsection{Microstructural analysis}

As observed in Fig. 3a and b, the grains in the base materials (BM) are large and unevenly distributed. Here, the grain sizes were measured by the software of ImageJ. 
The results of EDS (Fig. 3c and d) indicate that the white agglomerates in the Mg matrix are $\mathrm{MgO}$ (Fig. 3c). Due to the limited spot scanning size of EDS, it is inevitable to detect the Mg matrix. Therefore, the elements of $\mathrm{Zn}$ and $\mathrm{Ca}$ present in the results of EDS as well as $\mathrm{Mg}$ and $\mathrm{O}$. The area in Fig. $3 \mathrm{~d}$ is the regional $\mathrm{BM}$ of $\mathrm{Mg}-\mathrm{Zn}-\mathrm{Ca}$, where is no $\mathrm{MgO}$ from the EDS result. As found by Liu et al. [19], when $\mathrm{Mg}$, $\mathrm{Zn}$ and $\mathrm{Ca}$ are below $500{ }^{\circ} \mathrm{C}$, there is almost no oxidation. And the friction stir processing temperature of $\mathrm{Mg}$ alloy does not exceed $500{ }^{\circ} \mathrm{C}$ [20], which shows that in the composite material the element of $\mathrm{O}$ only exists in the $\mathrm{MgO}$ particles. The distribution of the grain size in the $\mathrm{BM}$ is displayed in Fig. $3 \mathrm{f}$, and the average grain size is approximately $1.78 \mu \mathrm{m}$. Goh et al. [8] have found that as an inhibitor, the addition of $\mathrm{MgO}$ can restrict grain growth. Fig. 3e shows the result of XRD analysis which was conducted to investigate the phases constituted during the FSP. The major diffraction peak is that of the $\alpha-\mathrm{Mg}$ matrix. Weak diffraction peaks of $\mathrm{MgO}$ and precipitated phases $\left(\mathrm{Ca}_{2} \mathrm{Mg}_{6} \mathrm{Zn}_{3}\right.$ and $\mathrm{Mg}_{\mathrm{x}} \mathrm{Zn}_{\mathrm{y}}$ alloy, including $\mathrm{MgZn}_{2}, \mathrm{Mg}_{2} \mathrm{Zn}_{3}$ and $\left.\mathrm{Mg}_{4} \mathrm{Zn}_{7}\right)$ are also observed. In this experiment, since the mass fraction of the added $\mathrm{MgO}$ is quite small, the diffraction peak of $\mathrm{MgO}$ in XRD is difficult to be inspected due to the power limit. 

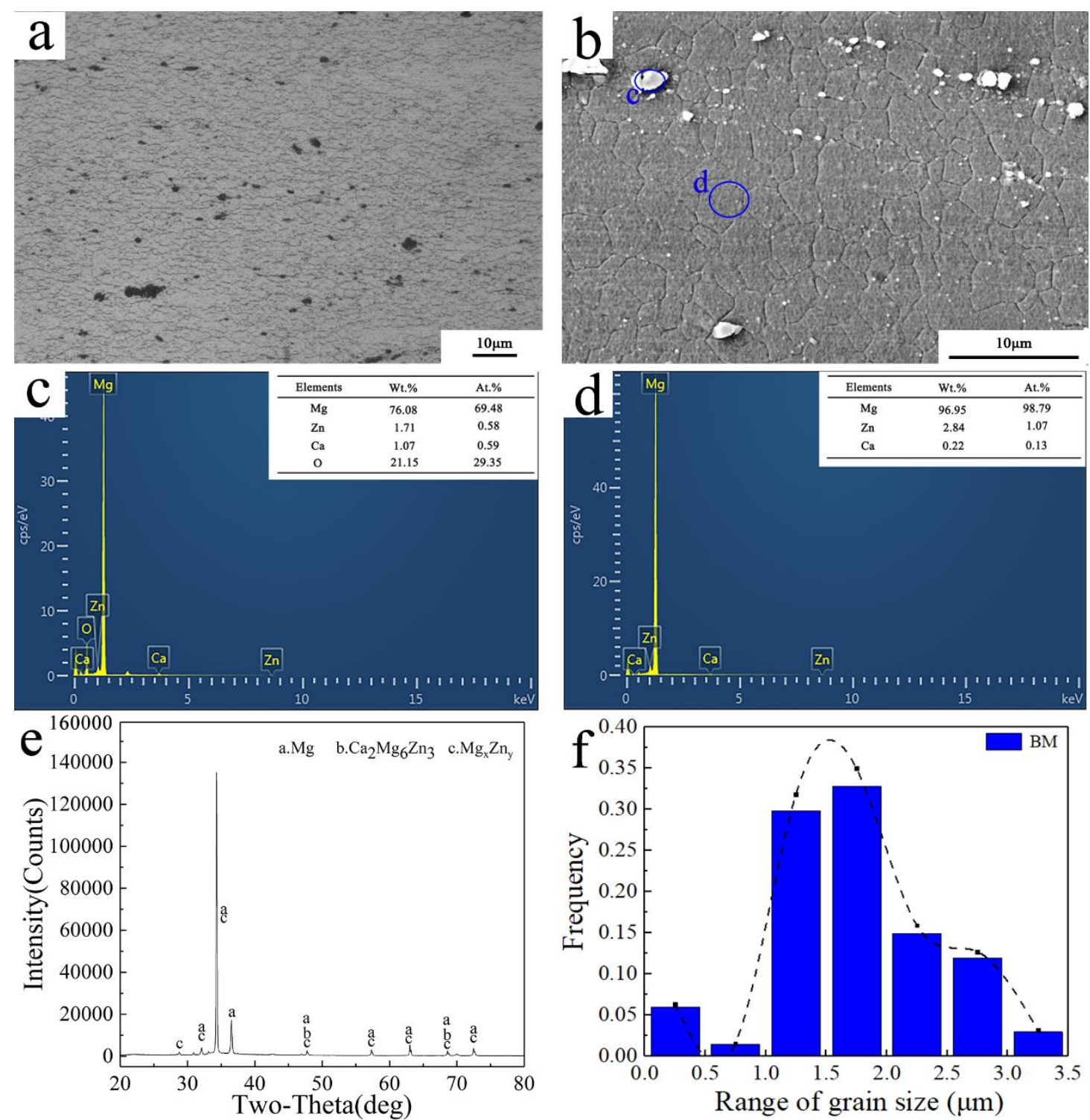

Fig. 3. $\mathrm{MgO} / \mathrm{Mg}-\mathrm{Zn}-\mathrm{Ca}$ composite (BM): (a) OM, (b) SEM, (c) EDS result of MgO, (d) EDS result of substrate, (e) XRD, (f) Grain size distribution.

Fig. $4 \mathrm{a}$ and $\mathrm{b}$ show the distribution of the $\mathrm{MgO}$ particles in the $\mathrm{BM}$ and the nugget zone (NZ) under SEM. The agglomeration of the $\mathrm{MgO}$ particles is a little serious in the BM. Compared to the $\mathrm{BM}$, the particles in $\mathrm{NZ}$ are smaller and more uniformly distributed. The maximum size of the particle in the BM reached $5.62 \mu \mathrm{m}$ while the size of the largest particle in the NZ is less than $2 \mu \mathrm{m}$. Most are in the nano-scale $(\leq 100 \mathrm{~nm})$, 
which can be attributed to the mechanical stirring and thermal effects during the FSP and related to the action of breaking up the particles and disperse them. Since the $\mathrm{MgO}$ particles cannot be observed in the NZ with the higher rotational speed due to the SEM magnification, Fig. 4 displays the NZ after 800 rpm, which is the lowest rotational speed in the parameters of the FSP processes for reference. The refining effect of $\mathrm{MgO}$ particles is limited for lower rotational speed, therefore the FSP-ed MgO particles have the largest sizes, and as for the subsequent higher rotational speed, the refining effect of particles is more apparent comparatively.
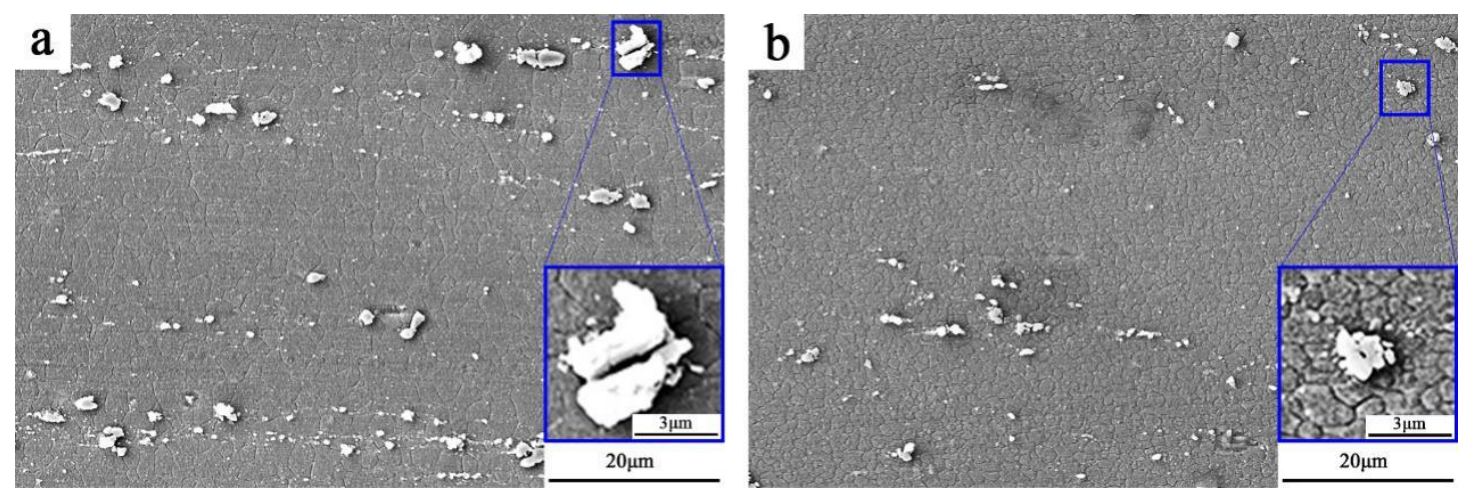

Fig. 4. Microscopic SEM under $800 \mathrm{rpm}-60 \mathrm{~mm} / \mathrm{min}$ : a) BM, b) NZ.

$\mathrm{NZ}$ is the key area for the FSP-ed samples because of its finer and more uniform microstructure. Therefore, the NZ of the samples was observed through SEM, as shown in Fig. 5. As mentioned above, the white particles in the matrix are $\mathrm{MgO}$. When the traveling speed was fixed at stirring speed of $800 \mathrm{rpm}$, the sizes of agglomerated $\mathrm{MgO}$ were relatively larger than those at stirring speed of $1000 \mathrm{rpm}$ and $1200 \mathrm{rpm}$. The higher stirring speed resulted in higher heat input, better fluidity of plastic metal, and stronger mechanical force which homogenized the microstructure in the NZ. 
Referring to the distribution of $\mathrm{MgO}$ in Fig. 5, it can be observed that the $\mathrm{MgO}$ is more uniformly distributed in the $\mathrm{Mg}$ matrix at $1200 \mathrm{rpm}-60 \mathrm{~mm} / \mathrm{min}$. More $\mathrm{MgO}$ clusters have been adverted in the metal matrix processed at $1200 \mathrm{rpm}-80 \mathrm{~mm} / \mathrm{min}$. The presence of smaller and more uniformly dispersed particles in the matrix processed at $1200 \mathrm{rpm}-60 \mathrm{~mm} / \mathrm{min}$ is also related to the rotational situation. At $1200 \mathrm{rpm}-60 \mathrm{~mm} / \mathrm{min}$ the rotational speed per unit distance is higher than that at $1200 \mathrm{rpm}-80 \mathrm{~mm} / \mathrm{min}$. Therefore, for the same distance, the sample processed at $1200 \mathrm{rpm}-60 \mathrm{~mm} / \mathrm{min}$ will be subjected to more stirring.
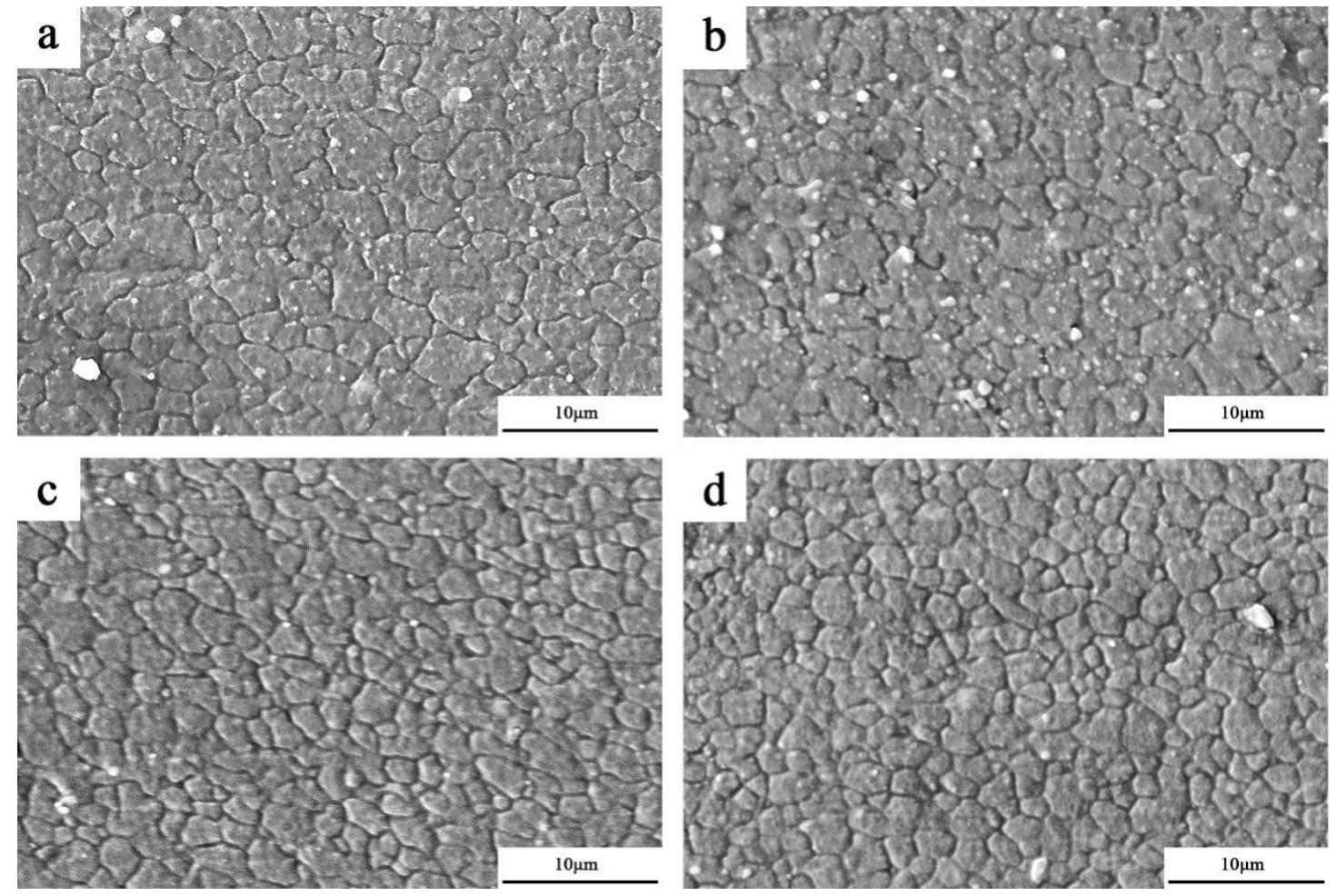

Fig. 5. SEM analysis of NZ under different parameters: (a) $800 \mathrm{rpm}-60 \mathrm{~mm} / \mathrm{min}$, (b) $1000 \mathrm{rpm}-60 \mathrm{~mm} / \mathrm{min}$, (c) $1200 \mathrm{rpm}-60 \mathrm{~mm} / \mathrm{min}$, (d) $1200 \mathrm{rpm}-80 \mathrm{~mm} / \mathrm{min}$.

Here, during the selection of the processing parameters, two points need to be taken into account. (1) Surface morphology. If the rotational speed is above $1200 \mathrm{rpm}$ 
and the traveling speed is over $80 \mathrm{~mm} / \mathrm{min}$, the surface quality of the sample is unacceptable based on the study. (2) Heat input. Considering that the ratio of $\omega / v$ changes in proportion to the heat input, and low heat input reduces the possibility of excessive grain growth. Therefore, the traveling speeds of $60 \mathrm{~mm} / \mathrm{min}$ and $80 \mathrm{~mm} / \mathrm{min}$ (poor shape forming when lower than $50 \mathrm{~mm} / \mathrm{min}$ ) were selected to compare the properties.

The distribution of the grain size in NZ at different processing parameters is shown in Fig. 6. When the parameters are $800 \mathrm{rpm}-60 \mathrm{~mm} / \mathrm{min}, 1000 \mathrm{rpm}-60 \mathrm{~mm} / \mathrm{min}$, and $1200 \mathrm{rpm}-60 \mathrm{~mm} / \mathrm{min}$, the average grain sizes were $1.08 \mu \mathrm{m}, 1.13 \mu \mathrm{m}$, and $1.04 \mu \mathrm{m}$, respectively. The increasing stirring speed led to higher heat input, better fluidity of the plastic metal, and higher mechanical force. When the parameter is $1000 \mathrm{rpm}-60$ $\mathrm{mm} / \mathrm{min}$, the grain size is slightly larger than $800 \mathrm{rpm}-60 \mathrm{~mm} / \mathrm{min}$ and $1200 \mathrm{rpm}-60$ $\mathrm{mm} / \mathrm{min}$, which is related to two factors, i.e. the stirring speed and the distribution of inhibitors. Moreover, based on the above results, the effect of agitation is greater than heat input in refining the grain size.

The average grain sizes of the NZ at $1200 \mathrm{rpm}-60 \mathrm{~mm} / \mathrm{min}$ and $1200 \mathrm{rpm}-80$ $\mathrm{mm} / \mathrm{min}$ are $1.04 \mu \mathrm{m}$ and $1.01 \mu \mathrm{m}$, respectively. The rotational speed per unit length at $60 \mathrm{~mm} / \mathrm{min}$ is higher than that at $80 \mathrm{~mm} / \mathrm{min}$, leading to more stirring for the same length. Meanwhile, higher rotational speed generates higher heat according to heat input, which is the direct reason for similar grain sizes of two procedures. 

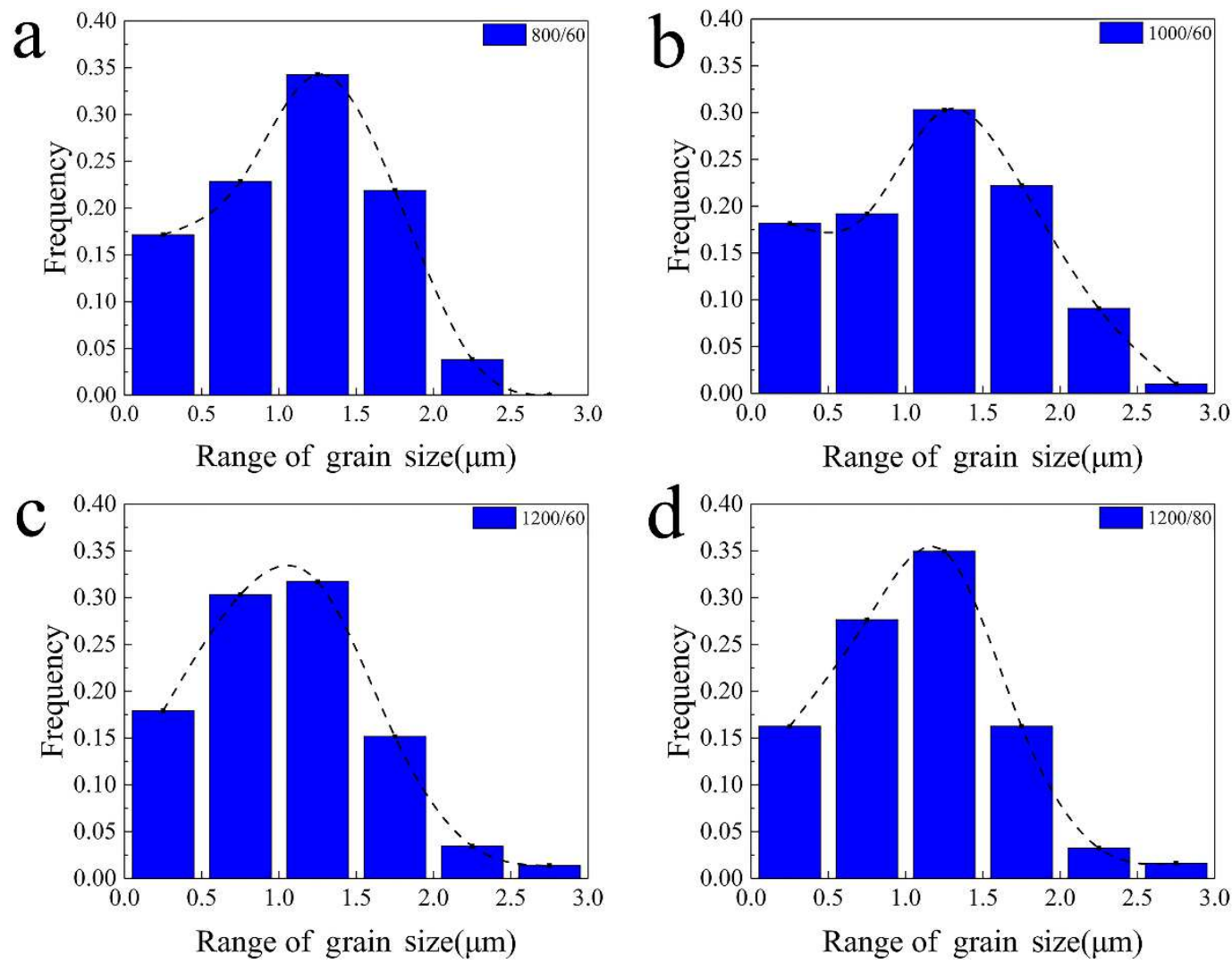

Fig. 6. Distribution of grain size of NZ under different parameters: (a) 800 rpm-60 mm/min, (b) $1000 \mathrm{rpm}-60 \mathrm{~mm} / \mathrm{min}$, (c) $1200 \mathrm{rpm}-60 \mathrm{~mm} / \mathrm{min}$, (d) $1200 \mathrm{rpm}-80$ $\mathrm{mm} / \mathrm{min}$.

Fig. 7 shows the results of the XRD analysis of the NZ under different parameters. XRD test results show that the materials treated with different parameters have similar phase types. In addition to the $\mathrm{Mg}$, the phases of $\mathrm{Ca}_{2} \mathrm{Mg}_{6} \mathrm{Zn}_{3}$ and $\mathrm{Mg}_{\mathrm{x}} \mathrm{Zn}_{\mathrm{y}}\left(\mathrm{MgZn}_{2}\right.$ 、 $\mathrm{Mg}_{2} \mathrm{Zn}_{3} 、 \mathrm{Mg}_{4} \mathrm{Zn}_{7}$ ) were also found, this is consistent with the phase ingredient of the $\mathrm{Mg}-\mathrm{Zn}$-Ca ternary alloy. The diffraction peaks of the Mg matrix are not as strong as those in the BM (Fig. 3e). The phase of $\mathrm{Mg}_{\mathrm{x}} \mathrm{Zn}_{\mathrm{y}}$ was reduced, which would improve the corrosion resistance. Song et al. [21] found that these phases may cause severe galvanic corrosion in the Mg matrix. Lu et al. [22] have shown that the Mg-3Zn phase 
present in the $\mathrm{Mg}-\mathrm{Zn}-\mathrm{Ca}$ alloy reduces the corrosion resistance. That is another reason for the NZ areas after the FSP owns higher corrosion resistance compared to the BM. By comparing the XRD results in Fig. 7 and Fig. 3, it was found that FSP did not change the phase types in NZ. However, according to the previous analysis, FSP changes the grain size and particle distribution.

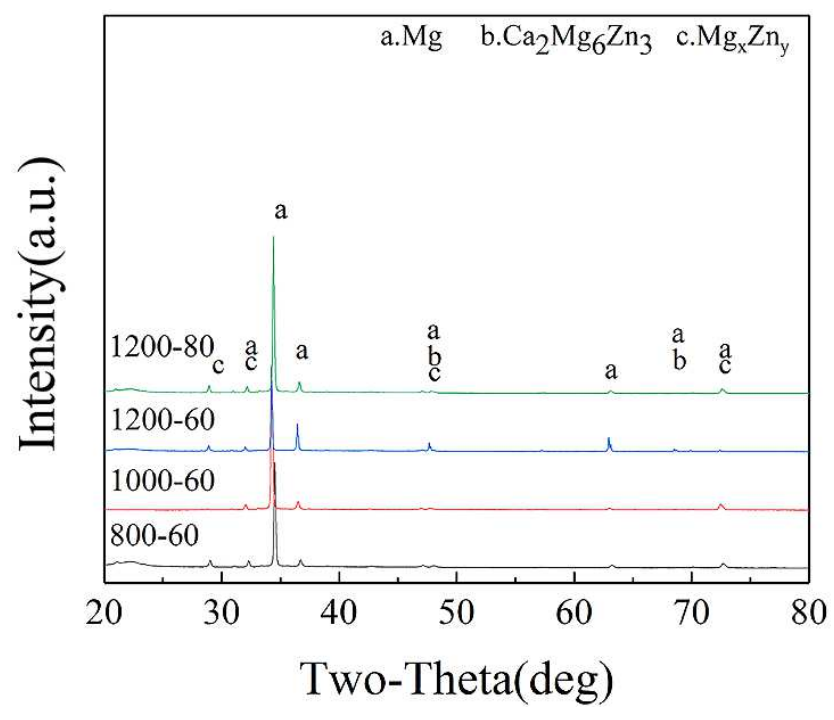

Fig. 7. XRD results of NZ under different parameters.

\subsection{Electrochemical Testing}

To study the general corrosion performance, i.e. pitting corrosion resistance, of the FSP-ed samples, the NZs with different parameters were electrochemically tested. The corrosion current $\left(I_{c o r r}\right)$, corrosion potential $\left(E_{c o r r}\right)$, cathode Tafel slope $\left(\beta_{c}\right)$ and anode Tafel slope $\left(\beta_{\alpha}\right)$ are listed in Table 3. In addition, according to the report of BakhsheshiRad et al. [23], the polarization resistance $\left(R_{p}\right)$ of the tested sample was calculated using the following equation (Equation 2): 


$$
R_{p}=\frac{\beta_{a} \beta_{c}}{2.303\left(\beta_{a}+\beta_{c}\right) I_{c o r r}}
$$

It can be seen from Fig. 8 that the kinetic potential polarization process under each procedure was controlled by the activation reaction at the cathode in a large range and exhibit different dynamic potential polarization behaviors. The sample produced at $1200 \mathrm{rpm}-60 \mathrm{~mm} / \mathrm{min}$ has the highest corrosion potential $\left(E_{\text {corr }}=-1.332 \mathrm{~V}\right)$, smaller corrosion current density $\left(I_{\text {corr }}=47.9 \mu \mathrm{A} / \mathrm{cm}^{2}\right)$ and larger polarization resistance $\left(R_{p}=\right.$ $\left.1.227 \mathrm{k} \Omega \cdot \mathrm{cm}^{2}\right)$.

In the polarization curve, the cathode side is controlled by the hydrogen release reaction in the aqueous solution, and the other side is the negative difference effect of the anode dissolution reaction, i.e., the dissolve of $\mathrm{Mg}$, and abnormal anode hydrogen release. Lin et al. [9] stated that the reduction reaction of hydrogen ions and the hydrogen overvoltage in cathode phase play a significant part in the corrosion of magnesium. The $\alpha-\mathrm{Mg}$ matrix preferentially dissolves as an electric anode, forming a porous $\mathrm{Mg}(\mathrm{OH})_{2}$ covering the interface, according to Song et al. [24]:

$$
\begin{gathered}
\mathrm{Mg} \rightarrow \mathrm{Mg}^{2+}+2 \mathrm{e}^{-} \quad \text { Anodic reaction } \\
2 \mathrm{H}_{2} \mathrm{O}+2 \mathrm{e}^{-} \rightarrow \mathrm{H}^{2+}+2 \mathrm{OH}^{-} \text {Cathodic reaction }
\end{gathered}
$$

It has a small corrosion driving force in the SBF solution, and the corrosion rate is slow. Using the same cathode potential, the electrode current of it has a larger cathode current density, and a more complete hydrogen evolution corrosion occurred, the anode side of all samples has a passivation tendency lower than the breakdown potential, which indicates the existence of a surface protective layer, this is mainly a dense $\mathrm{Mg}(\mathrm{OH})_{2}$ conservatory layer. When studying the passivation properties of $\mathrm{Mg}$ alloy, 
Cao et al. [25] proposed that generating a passivated surface is a crucial method to better the corrosion behavior of Mg alloy. And Ambat et al. [26] pointed out that the corrosion layer of $\mathrm{Mg}$ and $\mathrm{Mg}$ alloy surfaces is magnesium hydroxide.

During the anodic polarization process, the current of the sample was increased with the potential shift and exhibited a strong discharge activity. This is because the $\mathrm{MgO}$ particles are finer and more uniform in the sample produced at $1200 \mathrm{rpm}-60$ $\mathrm{mm} / \mathrm{min}$, and Lin et al. [7] proposed that the $\mathrm{MgO}$ particles are in a positive potential position during the etching. Research by Ho et al. [27] shows that grain refinement can cause an increase in corrosion resistance. When the particles are uniformly dispersed, the potential is high and the distribution is uniform and has a small grain size, so uniform corrosion will occur, thereby improving corrosion resistance. In the microstructure with serious particle agglomeration, the agglomerated particles will lead to increased local misorientation difference, and Wang et al. [28] pointed out that high local misorientation difference will destroy corrosion resistance. And the high potential difference will lead to severe pitting, which is detrimental to the final pitting corrosion resistance of the samples. 


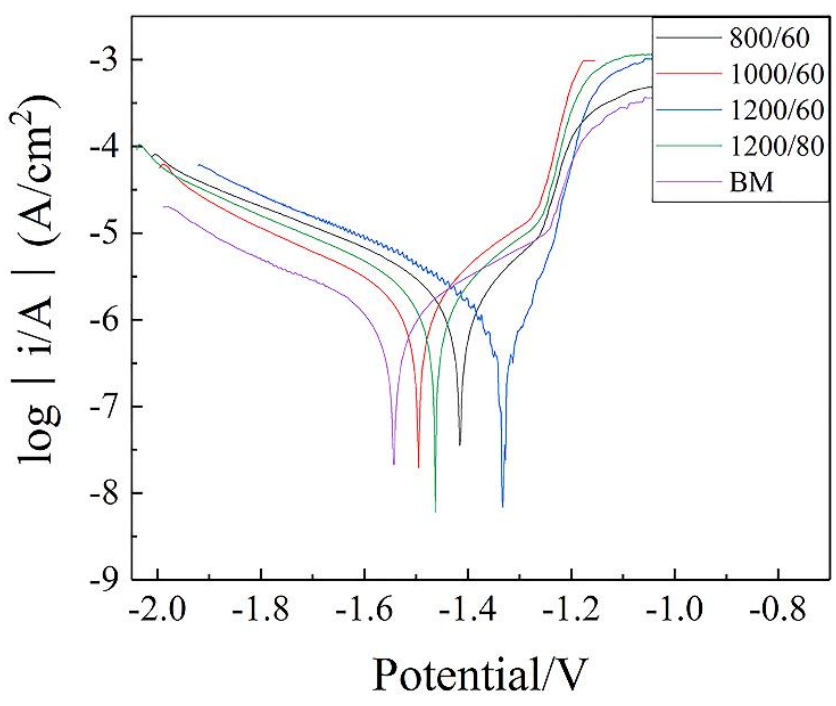

Fig. 8. Potential polarization curves of NZs in SBF solution under different parameters.

\section{Table 3}

Electrochemical parameters of NZs in SBF solution obtained by polarization test.

\begin{tabular}{cccccc}
\hline Sample & $E_{\text {corr }}$ & $I_{\text {corr }}$ & $\beta_{c}$ & $\beta_{\alpha}$ & $R_{p}$ \\
$(\mathrm{rpm} / \mathrm{mm} / \mathrm{min})$ & $(\mathrm{V})$ & $\left(\mu \mathrm{A} / \mathrm{cm}^{2}\right)$ & $(\mathrm{V} / \mathrm{dec})$ & $(\mathrm{V} / \mathrm{dec})$ & $\left(\mathrm{k} \Omega \cdot \mathrm{cm}^{2}\right)$ \\
\hline $800 / 60$ & -1.416 & 96.1 & 0.428 & 0.142 & 0.482 \\
$1000 / 60$ & -1.495 & 68.4 & 0.374 & 0.238 & 0.923 \\
$1200 / 60$ & -1.332 & 47.9 & 0.414 & 0.201 & 1.227 \\
$1200 / 80$ & -1.463 & 63.2 & 0.369 & 0.209 & 0.940 \\
$\mathrm{BM}$ & -1.542 & 57.7 & 0.327 & 0.223 & 0.960 \\
\hline
\end{tabular}

After electrochemical testing, the corrosion morphology was characterized. Fig.9 shows the corrosion morphology of BM and different parameters. The chromic acid solution is used to remove the corrosion products to judge the corrosion degree of the 
metal matrix. It can be seen from the figure that there are serious pitting-corrosion pits in the BM, while the area after FSP has a lot fewer pitting-corrosion pits. Because FSP refines the crystal grains, and makes the $\mathrm{MgO}$ particles fine and uniform. The study of Ralston et al. [29] showed that the corrosion resistance is directly related to the grain size. In the corrosion morphology of different parameters, when the parameter is $1200 \mathrm{rpm}-60 \mathrm{~mm} / \mathrm{min}$, the degree of corrosion is the lightest, the corrosion pits are small and there are a lot of flat areas. The research of Singla et al. [30] showed that the distribution of reinforcing particles could reduce the corrosion degree of composites. The distribution of $\mathrm{MgO}$ particles of $1200-60$ is the most uniform, so the degree of corrosion is also the lightest.
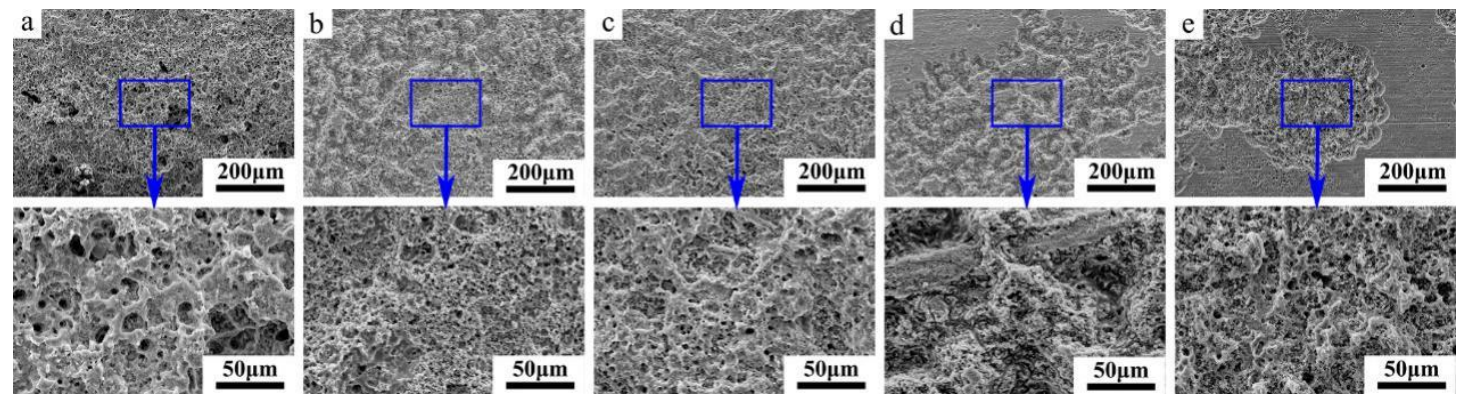

Fig. 9. Corrosion morphology of different parameters (removal of corrosion products): (a) BM, (b) $800 \mathrm{rpm}-60 \mathrm{~mm} / \mathrm{min}$, (c) $1000 \mathrm{rpm}-60 \mathrm{~mm} / \mathrm{min}$, (d) $1200 \mathrm{rpm}-$ $60 \mathrm{~mm} / \mathrm{min}$, (e) $1200 \mathrm{rpm}-80 \mathrm{~mm} / \mathrm{min}$. (The figure below is an enlarged view of the figure above.)

\subsection{Microhardness}

Microhardness tests were executed to systematically understand the 
microstructural evolution during the FSP. The results are presented in Fig. 10. Irrespective of the processing parameters, the NZ has the highest hardness. Compared to the $\mathrm{BM}$, the hardness of the $\mathrm{NZ}$ is approximately $35 \%$ higher due to grain size refinement as well as the presence of dispersed and fine $\mathrm{MgO}$ particles.

At the traveling velocity of $60 \mathrm{~mm} / \mathrm{min}$, the average hardness of the NZ was found to be $97.6 \mathrm{HV}, 97.0 \mathrm{HV}$ and $101.2 \mathrm{HV}$ for $800 \mathrm{rpm}, 1000 \mathrm{rpm}$ and $1200 \mathrm{rpm}$, respectively. When the parameter is $1200 \mathrm{rpm}-60 \mathrm{~mm} / \mathrm{min}$, the grain size is almost the smallest and the $\mathrm{MgO}$ particle distribution is the most uniform, leading to the highest hardness. Considering the influence of the different traveling velocities, the hardness of $1200 \mathrm{rpm}-80 \mathrm{~mm} / \mathrm{min}$ is $99.1 \mathrm{HV}$, which is lower than that of $1200 \mathrm{rpm}-60 \mathrm{~mm} / \mathrm{min}$. Table 4 offers the information for the grain size, hardness and $\omega / v$ value of the NZ. Compared to $1200 \mathrm{rpm}-80 \mathrm{~mm} / \mathrm{min}$, although the grains are a little larger at $1200 \mathrm{rpm}$ $60 \mathrm{~mm} / \mathrm{min}$, the larger $\omega / v$ results in a slightly higher hardness, which is related to the homogeneous distribution of the reinforcements in the NZ. Hence, it can be concluded that the reinforcing particles play a dominant role in strengthening the composite.

\section{Table 4}

Grain size, hardness and $\omega / v$ value of the samples.

\begin{tabular}{cccc}
\hline Sample (rpm-mm/min) & Grain Size $(\mu \mathrm{m})$ & Hardness $(\mathrm{HV})$ & $\omega / \nu$ \\
\hline $800-60$ & 1.08 & 97.6 & 13.3 \\
$1000-60$ & 1.13 & 97.0 & 16.6 \\
$1200-60$ & 1.04 & 101.2 & 20 \\
\hline
\end{tabular}


Besides the particle strengthening, it is well known that grain size refinement leads to improvement of strength according to the Hall Petch equation (Equation 5).

$$
\sigma_{s}=\sigma_{0}+k d^{-\frac{1}{2}}
$$

Where, $\sigma_{s}$ is the strength of the composite; $\sigma_{0}$ is the yield strength; $d$ is the average grain diameter, and $k$ is the influence coefficient of grain boundary on the strength. The strength of the composite will be increased with the decreasing average grain size, due to more grain boundaries, which impede crack growth. On the other hand, during the cooling of the composite, due to mechanical and thermodynamic mismatching between reinforcing particles and the matrix, residual stress exists at the interfaces, resulting in plastic rheology and then high-density dislocation in the matrix. These are the major reasons for the improvement of the composite hardness in this study. Mallmann et al. [31] used FSP to prepare Mg-based composites reinforced with $\mathrm{Y}_{2} \mathrm{O}_{3}$ particles, and studies have shown that the dislocation strengthening caused by added particles plays a major role in the strengthening mechanism. 

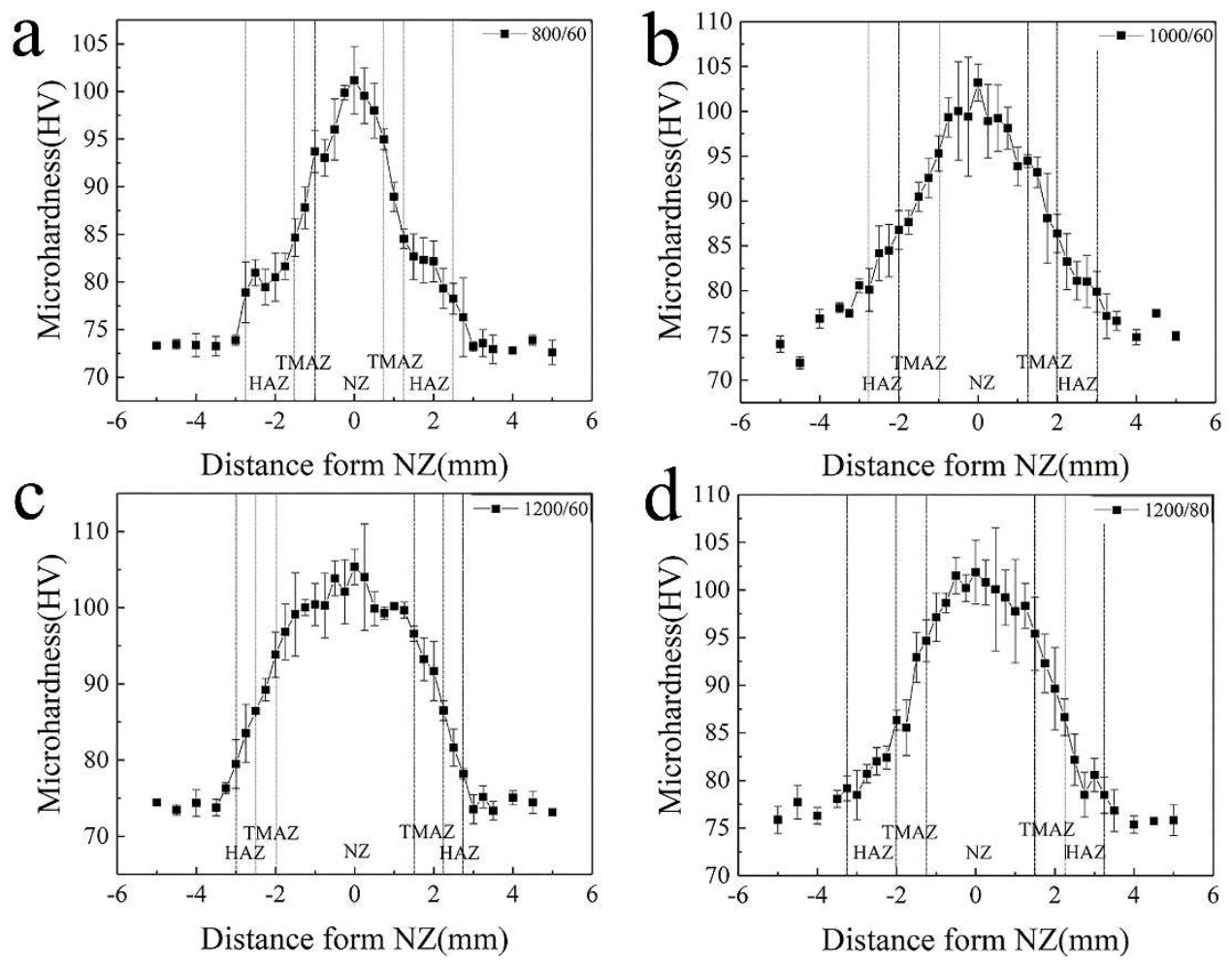

Fig. 10. Microhardness distribution of four welds under different parameters: (a) 800 rpm-60 mm/min, (b) $1000 \mathrm{rpm}-60 \mathrm{~mm} / \mathrm{min}$, (c) $1200 \mathrm{rpm}-60 \mathrm{~mm} / \mathrm{min}$, (d) $1200 \mathrm{rpm}-$ $80 \mathrm{~mm} / \mathrm{min}$.

Another phenomenon besides the hardness improvement is that the widths of the NZ under the different parameters varied, which attributed to the duration of the stirring action of the pin per unit length from Fig. 10. at $60 \mathrm{~mm} / \mathrm{min}$, the longer time per unit length would result in higher heat input, processing temperature and plastic deformation, and then a wider processing zone, as can been observed from Fig. $10 \mathrm{~b}$ and $\mathrm{c}$. Considering sampling components from the NZ for medical application, for instance bone nail, the width of the NZ is a factor to control during the real processing.

\subsection{Grain misorientation}

From the above, the sample performance is optimized with $1200 \mathrm{rpm}-60 \mathrm{~mm} / \mathrm{min}$. 
The sample produced under that condition was selected for EBSD characterization to investigate the correlation between grain misorientation and mechanical performance in different districts of the sample. Fig. 11 shows pole figures in different districts of the sample. It can be judged that the BM has a certain texture, and the grain orientation of the NZ is overall perpendicular to the ND-TD plane (or parallel to WD). As a transition region, the influenced zone is in the intermediate state of transforming from the initial texture of the BM to the texture of the base plane $\{0001\}$. This is because the grain misorientation is different in the $\mathrm{BM}$, and the orientation factor is different, which will lead to discontinuity in the strain tensor at the grain boundaries. This phenomenon can be interpreted by referring to the Sachs model, through research by Barnett et al. [32]. When $\mathrm{Mg}$ alloy is deformed at a temperature below $498 \mathrm{~K}$, its plastic deformation mechanisms are base plane slip and conical plane twin. During the stirring action of the pin, a considerable shear force would be generated, resulting in large deformation and formation of the fabric of $\{0001\}$ base surface. The number and degree of grain opening slip system are reduced due to the fact that the thermo-mechanically affected zone (TMAZ) is at the edge of the NZ and the fluidity is poor. Therefore, the grain orientation is not completely parallel to the $\{0001\}$ plane. 


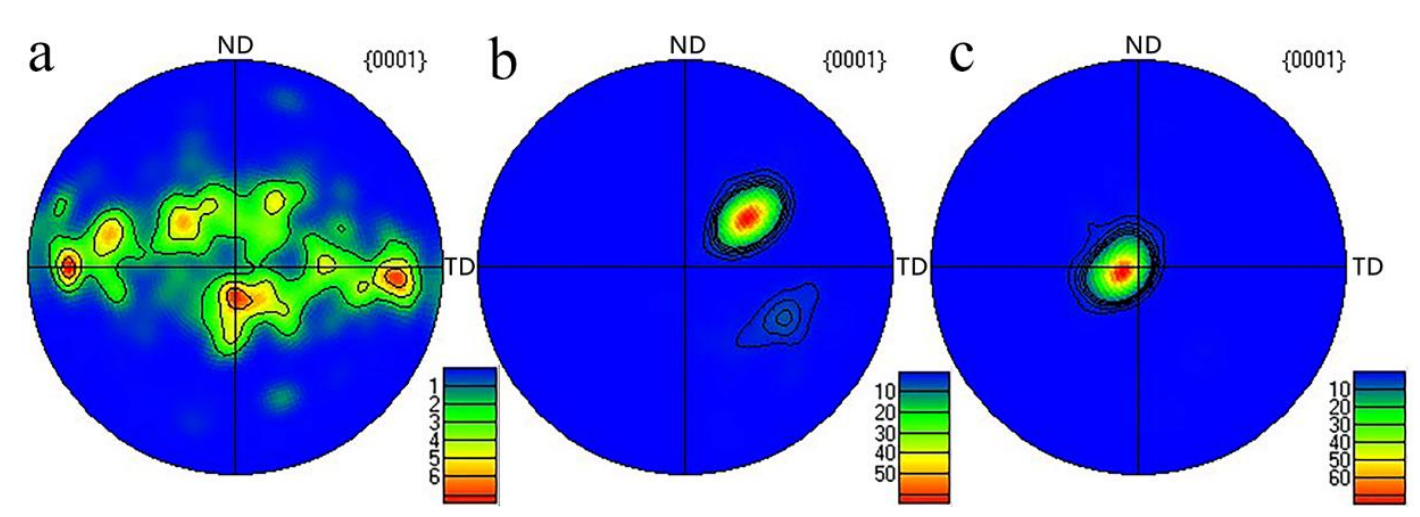

Fig. 11. $\{0001\}$ pole figures of grain orientation: (a) BM, (b) TMAZ, (c) NZ.

In Fig. 12a, c and e, the black solid line indicated the high-angle grain boundary (HAGB) $\left(\mathrm{HAGB}>15^{\circ}\right)$, and the green solid line represented the low-angle grain boundary (LAGB) $\left(2^{\circ}<\mathrm{LAGB}<15^{\circ}\right)$. The blue grains are fully recrystallized while the red grains are still deformed. It can be seen from the figures that there is more HAGB in the $\mathrm{BM}$ than in the NZ, i.e. the HAGB ratio is 0.87 , and the HAGB-ratio of NZ is 0.65 through statistical data. A large number of sawtooth grain boundaries easily become the nucleation site for recrystallization. The bulging grain boundary is to drive the movement of the slip system, which has an adverse effect on the hardness. In NZ, a large number of bulging grain boundaries were eliminated and many LAGBs were generated, which is related to the dislocation pile-up from the results, and then improve the hardness accordingly. The LAGB ratio of the TMAZ is 0.42 , more than that of the $\mathrm{NZ}, 0.35$, however, there are many incomplete grain boundaries. Although the TMAZ is influenced by mechanical agitation and generated heat, the degree is not as much as that of the NZ because it is at the edge of the processed core. Therefore, the heat is not enough for recrystallization after the stirring, resulting in incomplete grains. This is also a reason for the lower hardness in the TMAZ compared to NZ. 
Figs. $12 \mathrm{~b}, \mathrm{~d}$ and $\mathrm{f}$ show the distributions of misorientation angles in the BM, TMAZ, and NZ. Known by the correlated-grain misorientation, most misorientation angles in the $\mathrm{BM}$ is between $35^{\circ}$ and $65^{\circ}$, and misorientation angles were significantly reduced in the NZ and TMAZ, i.e. between $2^{\circ}$ and $30^{\circ}$. This is because in the processing, the stirring pin has experienced strong torsion and extrusion process which is helpful to the formation of a considerable number of dislocations. Usually, these dislocations appear as LAGBs. The peak values with different positions of uncorrelated grain orientation and theoretical grain orientation indicate the existence of texture. As shown in Fig. 12f, the grain boundary angle of the NZ has a peak at $30^{\circ}$. The hexagonal symmetry of hexagonal closed-packed (HCP) structure limits the effective increase of grain orientation difference during dynamic recrystallization and there is an orientation relationship of $30^{\circ}<0001>$. Fig. $12 \mathrm{e}$ also shows that part grains in the NZ were formed by dynamic recrystallization. During the stirring process, the grains were broken mechanically for the first step, and then dynamic recrystallization occurred due to the action of heat to form new grains. All these changes for the NZ are positive to the mechanical and even corrosion resistance of this area. 

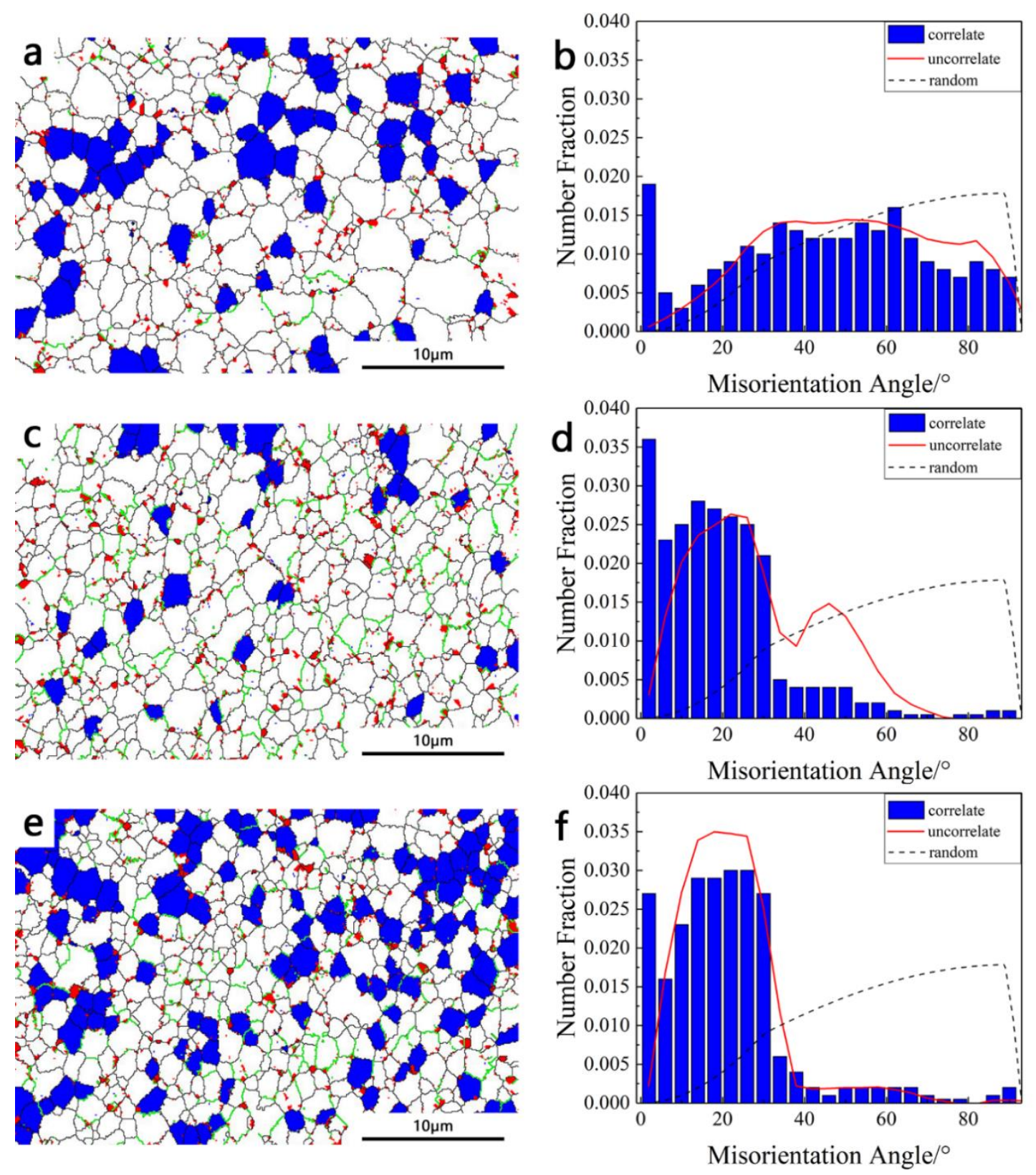

Fig. 12. Misorientation distribution and grain boundary images of BM, TMAZ and

NZ: (a) Grain boundary images of BM; (b) Misorientation-angle distributions of BM;

(c) Grain boundary maps of TMAZ; (d) Misorientation-angle distributions of TMAZ;

(e) Grain boundary maps of NZ; (f) Misorientation-angle distributions of NZ.

\section{Conclusions}

In this research, the novel $\mathrm{MgO} / \mathrm{Mg}-\mathrm{Zn}-\mathrm{Ca}$ matrix composite was created through 
optimized casting, and further friction stir processed to optimize the microstructure and properties. The conclusions are as follows.

(1) The key processing parameters of $1200 \mathrm{rpm}-60 \mathrm{~mm} / \mathrm{min}$ have created an FSPed sample with the best quality compared to the other procedures. The surface morphology is in good quality, and the reinforced particles are distributed uniformly.

(2) As for the FSP-ed sample using the appropriate solution, i.e. $1200 \mathrm{rpm}-60$ $\mathrm{mm} / \mathrm{min}$, the grain size is refined by $42 \%$, and as a result, the hardness is improved by $40 \%$ through both fine-grain strengthening and nanoparticle strengthening. According to comparison, particle strengthening is dominant in the strengthening mechanism.

(3) Compared to the BM specimens, the NZ specimens are more susceptible to corrosion. The specimens produced under $1200 \mathrm{rpm}-60 \mathrm{~mm} / \mathrm{min}$ exhibited the highest corrosion potential and polarization resistance as well as the smallest corrosion current density. In others word, these specimens represent the best general corrosion resistance.

(4) In the NZ of the sample after the FSP under $1200 \mathrm{rpm}-60 \mathrm{~mm} / \mathrm{min},\{0001\}$ basal texture and fully recrystallized grains were formed, which is beneficial to the properties.

In sum, the FSP is beneficial to the property improvement of the innovative composite by $\mathrm{Mg}-\mathrm{Zn}-\mathrm{Ca}$ and $\mathrm{MgO}$ nanoparticles, mainly mechanical properties and corrosion resistance. This is the first step for the research of the novel composite that will be applied in medical application, and it has been testified that from the points of mechanical and corrosion properties, the new-designed composite is acceptable. 


\section{Declarations}

\section{Acknowledgments}

The authors are grateful to Tianjin University for the assistance on FSP experiments.

\section{Funding}

This work was supported by the National Natural Science Foundation of China [U1764254], the National Natural Science Foundation of China [51871166], and Major science and Technology projects in Tianjin [No. 15ZXQXSY00080].

\section{Conflict of interest}

The authors declare no competing interests.

\section{Availability of data and material}

Not applicable.

\section{Code availability}

Not applicable.

\section{Author contribution}

Liu Zhen: Methodology, Formal analysis, Writing - Original. Cai Yangchuan: Investigation, Writing - Review \& Editing. Chen Jie: Data Curation. Han Jian: Writing - Review \& Editing, Project administration. Mao Zhiyong: Funding acquisition. Chen Minfang: Resources, Funding acquisition. 


\section{References}

[1] Islam R, Hadadzadeh A, Wells M, Haghshenas M. (2020) Thermomechanical processing of an ultralight Mg-14Li-1Al alloy. Int J Adv Manuf Technol,110:32213239. https://doi.org/10.1007/s00170-020-06032-z

[2] Moradnezhad S, Razaghian A, Taghiabadi R, Abedi HR, Salandari-Rabori A, Emamy M. (2019) Effect of $\mathrm{Ca}$ additions on evolved microstructures and subsequent mechanical properties of a cast and hot-extruded $\mathrm{Mg}-\mathrm{Zn}-\mathrm{Zr}$ magnesium alloy. Int J Adv Manuf Technol,104:4265-4275. https://doi.org/10.1007/s00170-019-04260-6

[3] Naser AZ, Darras BM. (2017) Experimental investigation of $\mathrm{Mg} / \mathrm{SiC}$ composite fabrication via friction stir processing. Int J Adv Manuf Technol,91:781-790. https://doi.org/10.1007/s00170-016-9801-z

[4] Chen L, Yao Y. (2014) Processing, Microstructures, and Mechanical Properties of Magnesium Matrix Composites: A Review. Acta Metall Sin-Engl,27:762-774. https://doi.org/10.1007/s40195-014-0161-0

[5] Jaiswal S, Kumar RM, Gupta P, Kumaraswamy M, Roy P, Lahiri D. (2018) Mechanical, corrosion and biocompatibility behaviour of Mg-3Zn-HA biodegradable composites for orthopaedic fixture accessories. J Mech Behav Biomed,78:442-454. https://doi.org/10.1016/j.jmbbm.2017.11.030

[6] Liu D, Zuo Y, Meng W, Chen M, Fan Z. (2012) Fabrication of biodegradable nanosized $\beta$-TCP/Mg composite by a novel melt shearing technology. Mater Sci Eng C,32:1253-1258. https://doi.org/10.1016/j.msec.2012.03.017 
[7] Lin G, Liu D, Chen M, You C, Li Z, Wang Y, Li W. (2018) Preparation and characterization of biodegradable $\mathrm{Mg}-\mathrm{Zn}-\mathrm{Ca} / \mathrm{MgO}$ nanocomposites for biomedical applications. Mater Charact,144:120-130. https://doi.org/10.1016/j.matchar.2018.06.028

[8] Goh CS, Gupta M, Wei J, Lee LC. (2007) Characterization of High Performance $\mathrm{Mg} / \mathrm{MgO} \quad$ Nanocomposites. J Compos Mater,41:2325-2335. https://doi.org/10.1177/0021998307075445

[9] Khalajabadi SZ, Abdul Kadir MR, Izman S, Marvibaigi M. (2016) The effect of $\mathrm{MgO}$ on the biodegradation, physical properties and biocompatibility of a $\mathrm{Mg} / \mathrm{HA} / \mathrm{MgO}$ nanocomposite manufactured by powder metallurgy method. J Alloy Compd,655:266-280. https://doi.org/10.1016/j.jallcom.2015.09.107

[10]Lei T, Tang W, Cai S, Feng F, Li N. (2012) On the corrosion behaviour of newly developed biodegradable Mg-based metal matrix composites produced by in situ reaction. Corros Sci,54:270-277. https://doi.org/10.1016/j.corsci.2011.09.027

[11]Bae S, Jung KH, Shin Y, Yoon DJ, Kawasaki M. (2016) Development of mechanical properties in a $\mathrm{CaO}$ added $\mathrm{AZ31}$ magnesium alloy processed by equalchannel angular pressing. Mater Charact,112:105-112. https://doi.org/10.1016/j.matchar.2015.12.009

[12]Arokiasamy S, Anand Ronald B. (2017) Experimental investigations on the enhancement of mechanical properties of magnesium-based hybrid metal matrix composites through friction stir processing. Int J Adv Manuf Technol,93:493-503. https://doi.org/10.1007/s00170-017-0221-5 
[13] Vandana B, Syamala P, Venugopal DS, Sk SRKI, Venkateswarlu B, Jagannatham M, Kolenčík M, et al. (2019) Magnesium/fish bone derived hydroxyapatite composites by friction stir processing: studies on mechanical behaviour and corrosion resistance. B Mater Sci,42. https://doi.org/10.1007/s12034-019-1799-z

[14]Morisada Y, Fujii H, Nagaoka T, Fukusumi M. (2006) MWCNTs/AZ31 surface composites fabricated by friction stir processing. Mater Sci Eng A,419:344-348. https://doi.org/10.1016/j.msea.2006.01.016

[15] Sahraeinejad S, Izadi H, Haghshenas M, Gerlich AP. (2015) Fabrication of metal matrix composites by friction stir processing with different Particles and processing parameters. Mater Sci Eng A,626:505-513. https://doi.org/10.1016/j.msea.2014.12.077

[16]Lee CJ, Huang JC, Hsieh PJ. (2006) Mg based nano-composites fabricated by friction stir processing. Scripta Mater,54:1415-1420. https://doi.org/10.1016/j.scriptamat.2005.11.056

[17] Asadi P, Faraji G, Besharati MK. (2010) Producing of AZ91/SiC composite by friction stir processing (FSP). Int $\mathrm{J}$ Adv Manuf Technol,51:247-260. https://doi.org/10.1007/s00170-010-2600-z

[18] Abbasi Gharacheh M, Kokabi AH, Daneshi GH, Shalchi B, Sarrafi R. (2006) The influence of the ratio of "rotational speed/traverse speed" $(\omega / \mathrm{v})$ on mechanical properties of AZ31 friction stir welds. Int J Mach Tool Manu,46:1983-1987. https://doi.org/10.1016/j.ijmachtools.2006.01.007 
[19]Liu Z, Li F, Feng Y, Meng Q. (1996) Influence of Ca and Zn on the Hightemperature Oxidation Resistance and Room-temperature Mechanical Property of $\mathrm{Mg}$ in As-cast Condition. Journal of Harbin University of Science and Technology:35-38.

[20] Woo W, Feng Z, Clausen B, David SA. (2017) In situ neutron diffraction analyses of temperature and stresses during friction stir processing of $\mathrm{Mg}-3 \mathrm{Al}-1 \mathrm{Zn}$ $\begin{array}{llll}\text { magnesium } & \text { alloy. } & \text { Mater } & \text { Lett,196:284-287. }\end{array}$ https://doi.org/10.1016/j.matlet.2017.03.117

[21] Song Y, Han E, Shan D, Yim CD, You BS. (2012) The role of second phases in the corrosion behavior of $\mathrm{Mg}-5 \mathrm{Zn}$ alloy. Corros Sci,60:238-245. https://doi.org/10.1016/j.corsci.2012.03.030

[22]Lu Y, Bradshaw AR, Chiu YL, Jones IP. (2015) Effects of secondary phase and grain size on the corrosion of biodegradable $\mathrm{Mg}-\mathrm{Zn}-\mathrm{Ca}$ alloys. Mater Sci Eng C,48:480-486. https://doi.org/10.1016/j.msec.2014.12.049

[23] Bakhsheshi-Rad HR, Abdul-Kadir MR, Idris MH, Farahany S. (2012) Relationship between the corrosion behavior and the thermal characteristics and microstructure of $\mathrm{Mg}-0.5 \mathrm{Ca}-\mathrm{xZn}$ alloys. Corros Sci,64:184-197.

https://doi.org/10.1016/j.corsci.2012.07.015

[24] Song GL, Atrens A. (1999) Corrosion Mechanisms of Magnesium Alloys. Adv Eng Mater:11-33. https://doi.org/10.1002/(SICI)1527-2648(199909)1:1<11::AIDADEM11>3.0.CO;2-N 
[25] Cao F, Song G, Atrens A. (2016) Corrosion and passivation of magnesium alloys. Corros Sci,111:835-845. https://doi.org/10.1016/j.corsci.2016.05.041

[26]Ambat R, Aung NN, Zhou W. (2000) Evaluation of microstructural e ects on corrosion behaviour of AZ91D magnesium alloy. Corros Sci:1433-1455.

[27]Ho Y, Joshi SS, Wu T, Hung C, Ho N, Dahotre NB. (2020) In-vitro bio-corrosion behavior of friction stir additively manufactured AZ31B magnesium alloyhydroxyapatite composites. Mater Sci Eng C,109:110632. https://doi.org/10.1016/j.msec.2020.110632

[28] Wang W, Wu H, Sun Y, Yan J, Zhang L, Zhang S, Ni J, et al. (2020) Local intragranular misorientation accelerates corrosion in biodegradable Mg. Acta Biomater,101:575-585. https://doi.org/10.1016/j.actbio.2019.10.036

[29]Ralston KD, Birbilis N, Davies CHJ. (2010) Revealing the relationship between grain size and corrosion rate of metals. Scripta Mater,63:1201-1204. https://doi.org/10.1016/j.scriptamat.2010.08.035

[30] Singla S, Singh Kang A, Sidhu TS. (2020) Characterization and electrochemical corrosion behaviour of FSPed WE43/nano-SiC surface composite. Materials Today: Proceedings,26:3138-3144. https://doi.org/10.1016/j.matpr.2020.02.647

[31] Mallmann C, Hannard F, Ferrié E, Simar A, Daudin R, Lhuissier P, Pacureanu A, et al. (2019) Unveiling the impact of the effective particles distribution on strengthening mechanisms: A multiscale characterization of $\mathrm{Mg}+\mathrm{Y} 2 \mathrm{O} 3$ nanocomposites. $\quad$ Mater Sci Eng A,764:138170. https://doi.org/10.1016/j.msea.2019.138170 
[32] Barnett MR, Keshavrz Z, Ma X. (2006) A semianalytical sachs model for the flow stress of a magnesium alloy. Metall Mater Tran A,37:2283-2293. 
Figures
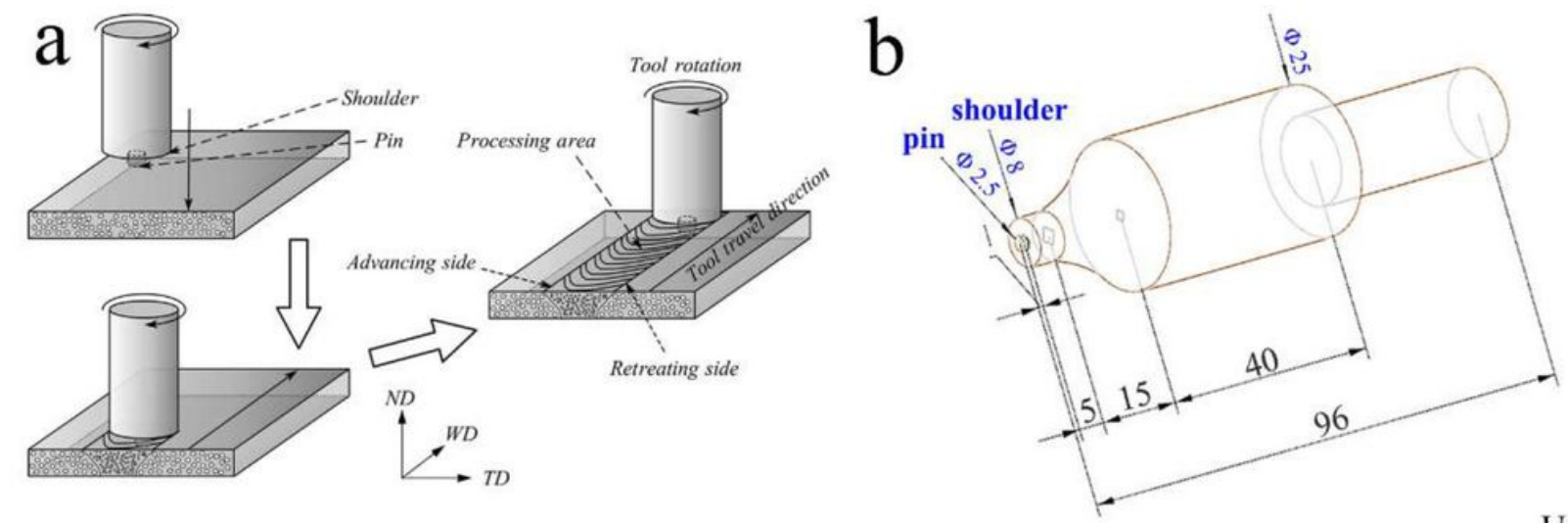

Unit:mm

\section{Figure 1}

(a) Schematic illustration of FSP process (WD-welding direction, ND-normal direction, TD-transverse direction); (b) Design of stirring pin.
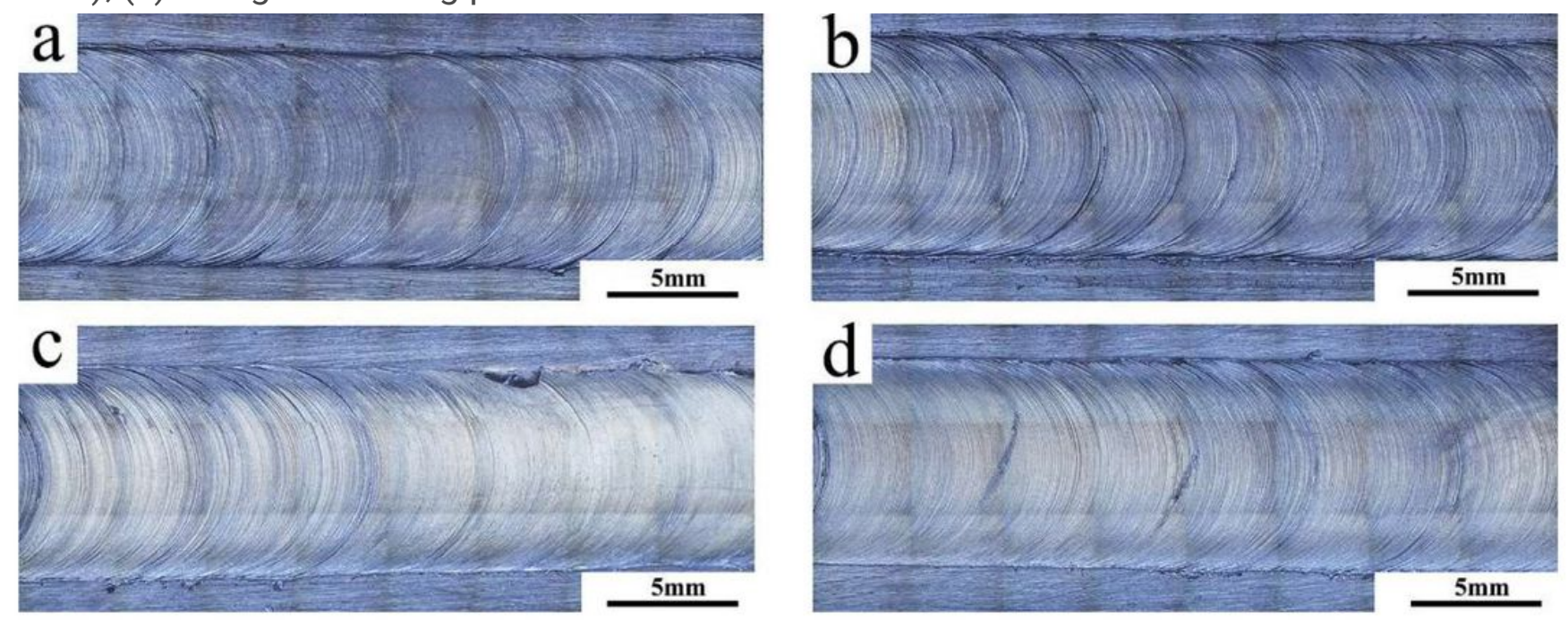

Figure 2

Macroscopic morphology of FSP samples with different parameters: (a) $800 \mathrm{rpm}-60 \mathrm{~mm} / \mathrm{min}$, (b) 1000 rpm-60 mm/min, (c) $1200 \mathrm{rpm}-60 \mathrm{~mm} / \mathrm{min}$, (d) $1200 \mathrm{rpm}-80 \mathrm{~mm} / \mathrm{min}$. 

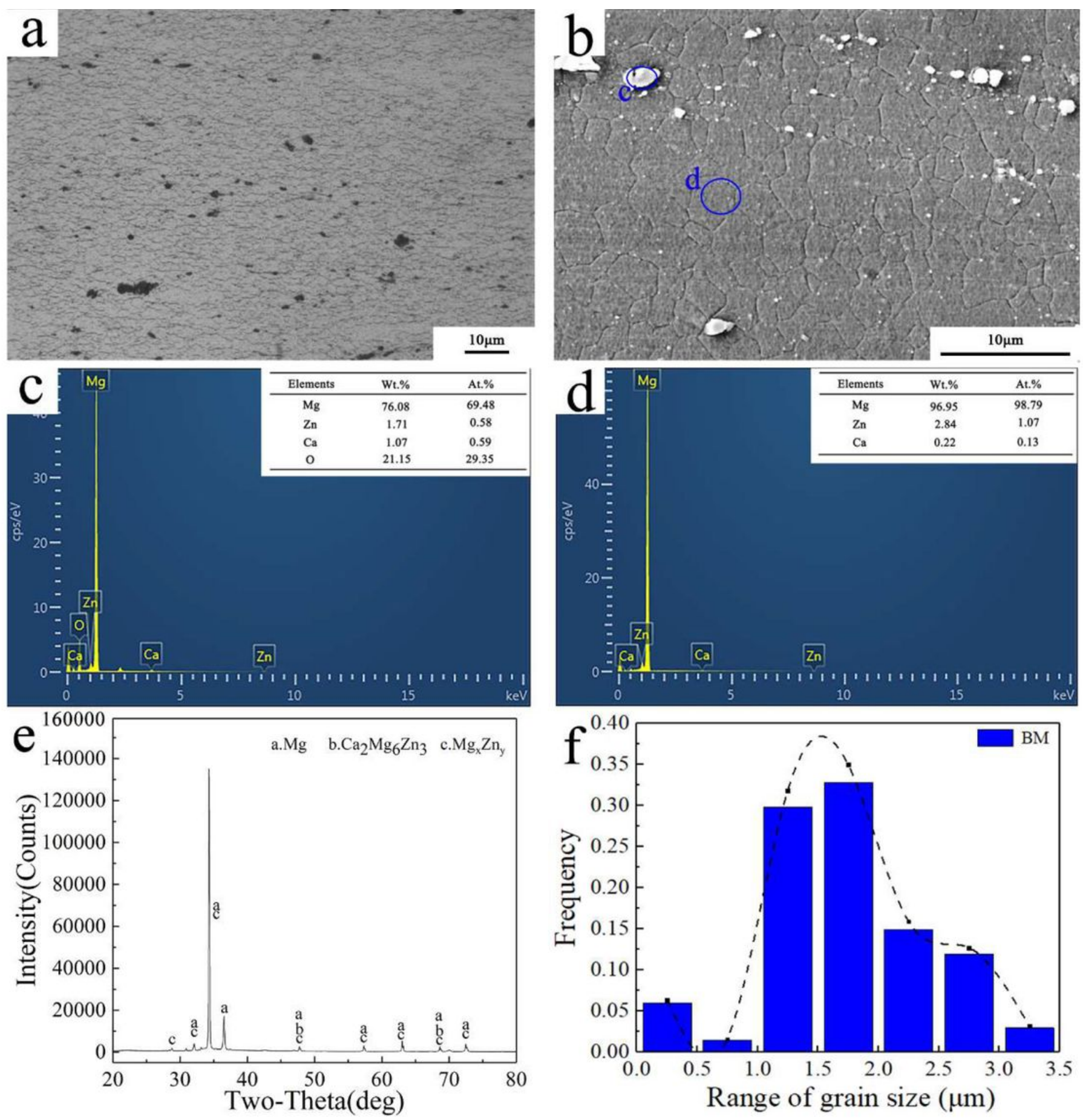

Figure 3

MgO/Mg-Zn-Ca composite (BM): (a) OM, (b) SEM, (c) EDS result of MgO, (d) EDS result of substrate, (e) XRD, (f) Grain size distribution. 

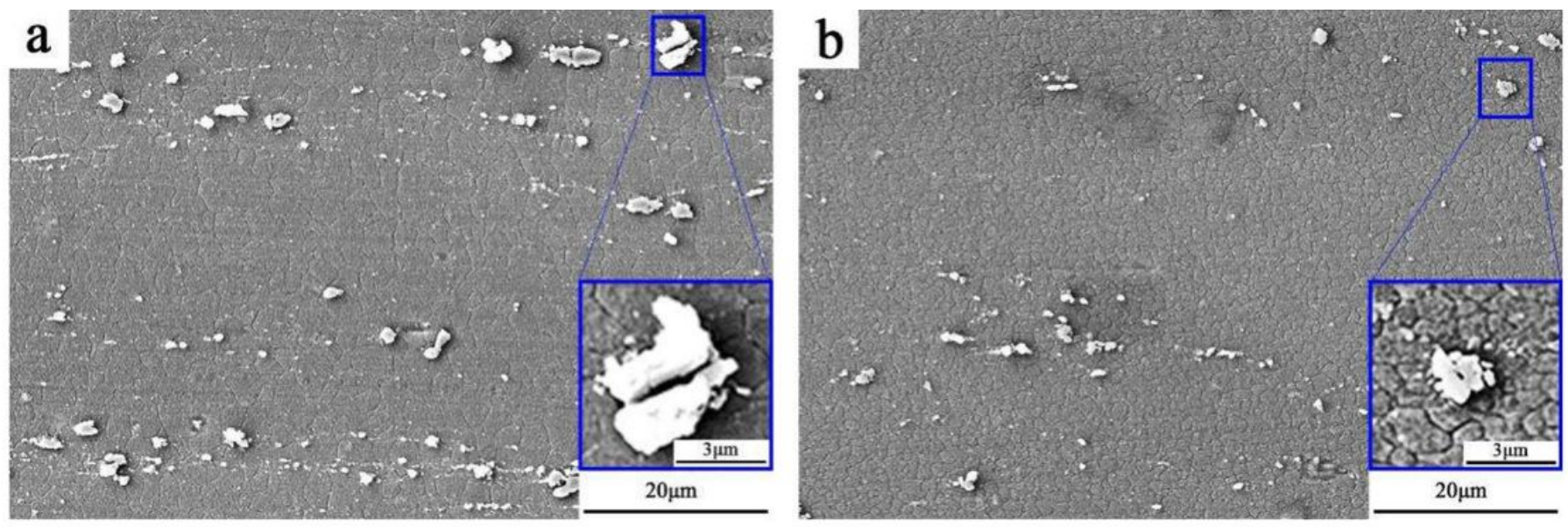

Figure 4

Microscopic SEM under $800 \mathrm{rpm}-60$ mm/min: a) BM, b) NZ.
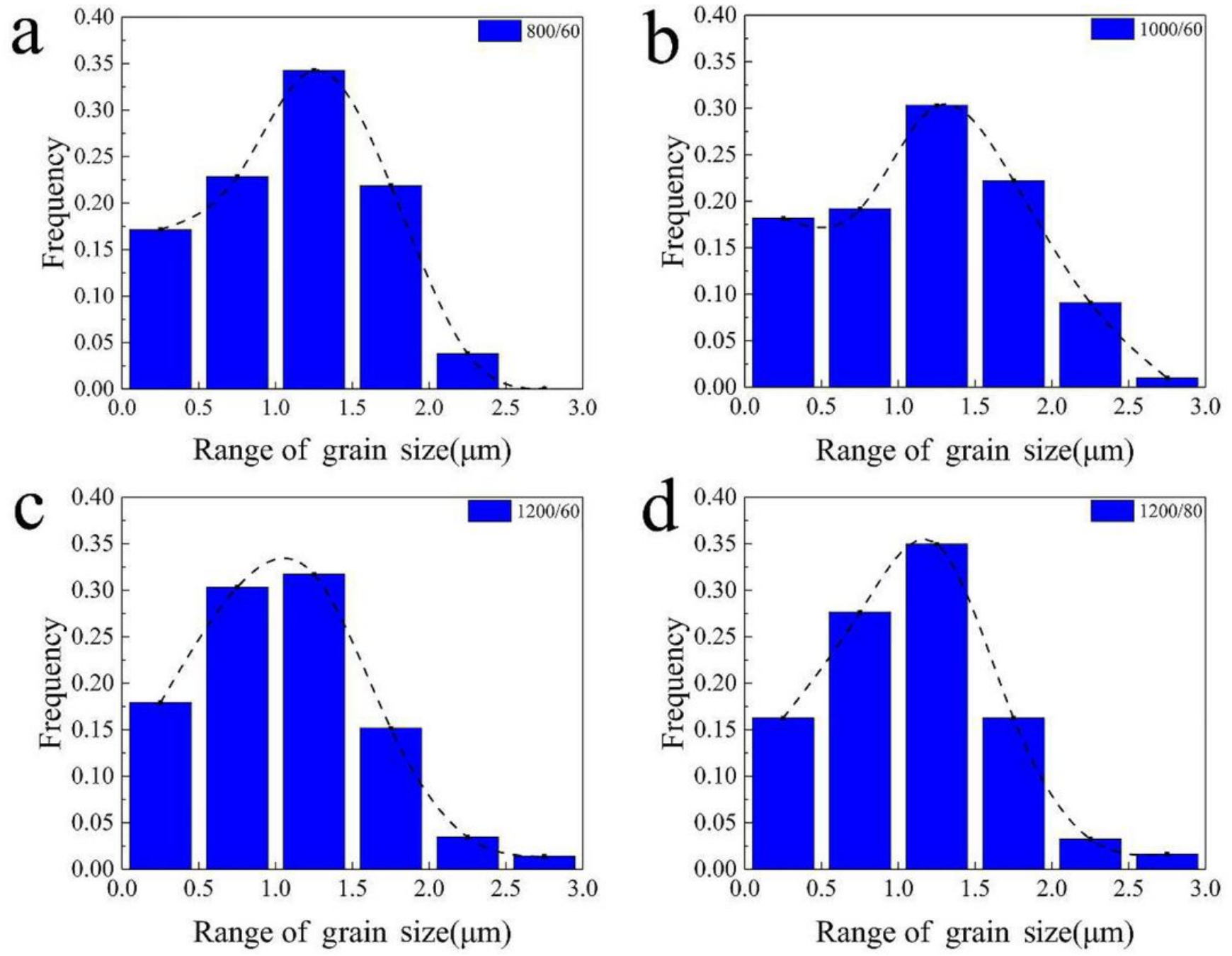

Figure 6 
Distribution of grain size of NZ under different parameters: (a) $800 \mathrm{rpm}-60 \mathrm{~mm} / \mathrm{min}$, (b) $1000 \mathrm{rpm}-60$ $\mathrm{mm} / \mathrm{min}$, (c) $1200 \mathrm{rpm}-60 \mathrm{~mm} / \mathrm{min}$, (d) $1200 \mathrm{rpm}-80 \mathrm{~mm} / \mathrm{min}$.

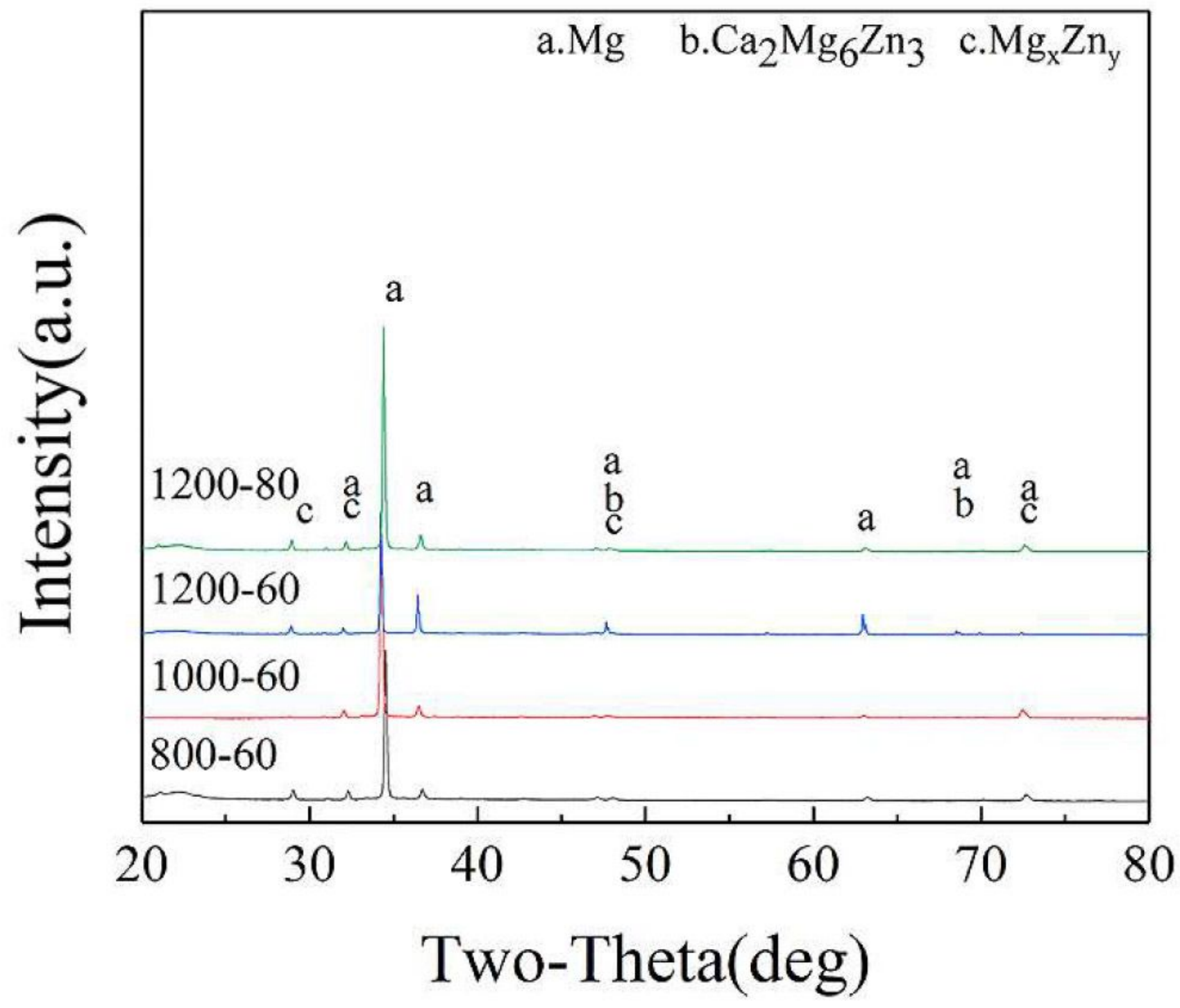

Figure 7

$\mathrm{XRD}$ results of NZ under different parameters. 


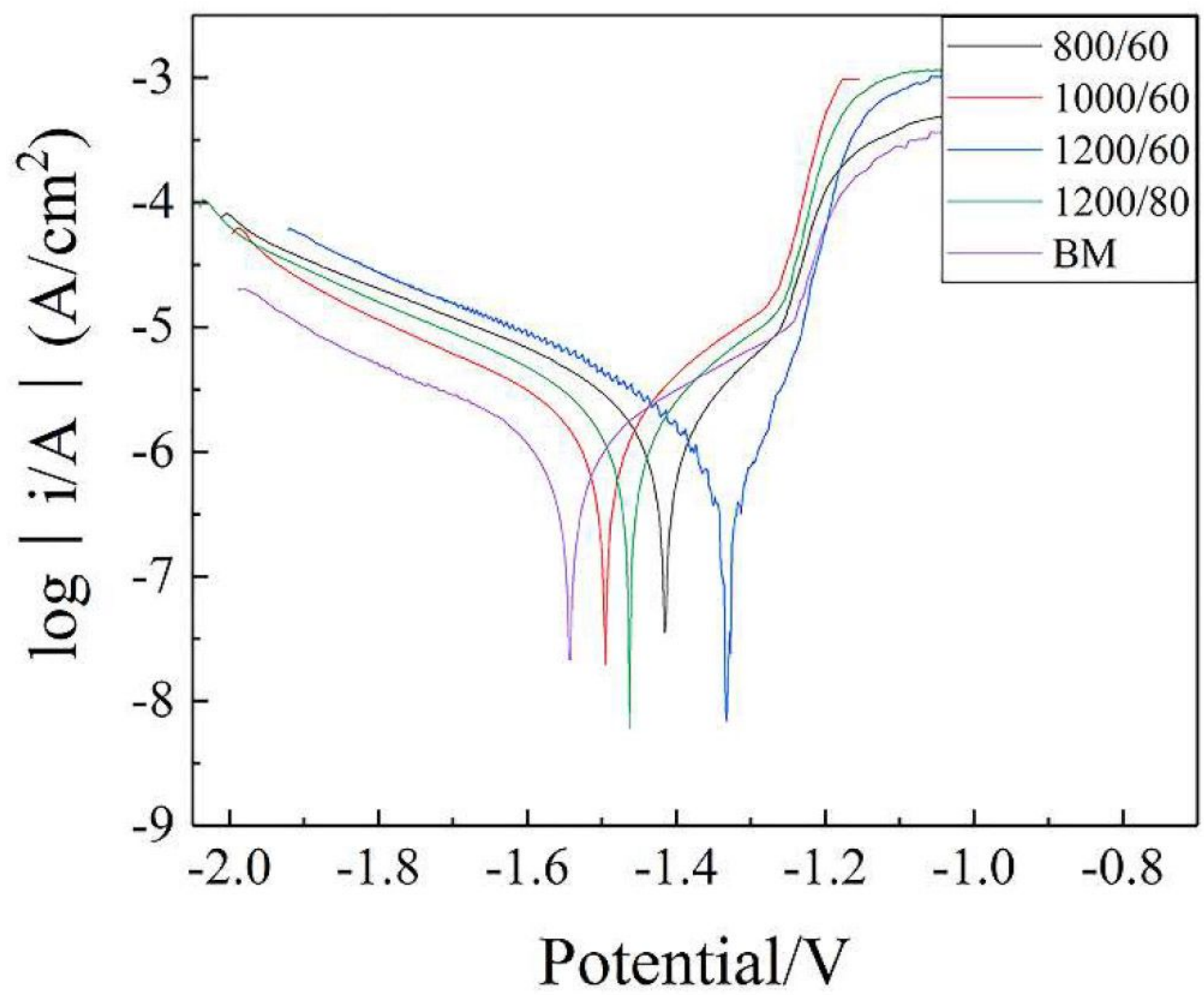

Figure 8

Potential polarization curves of NZs in SBF solution under different parameters.
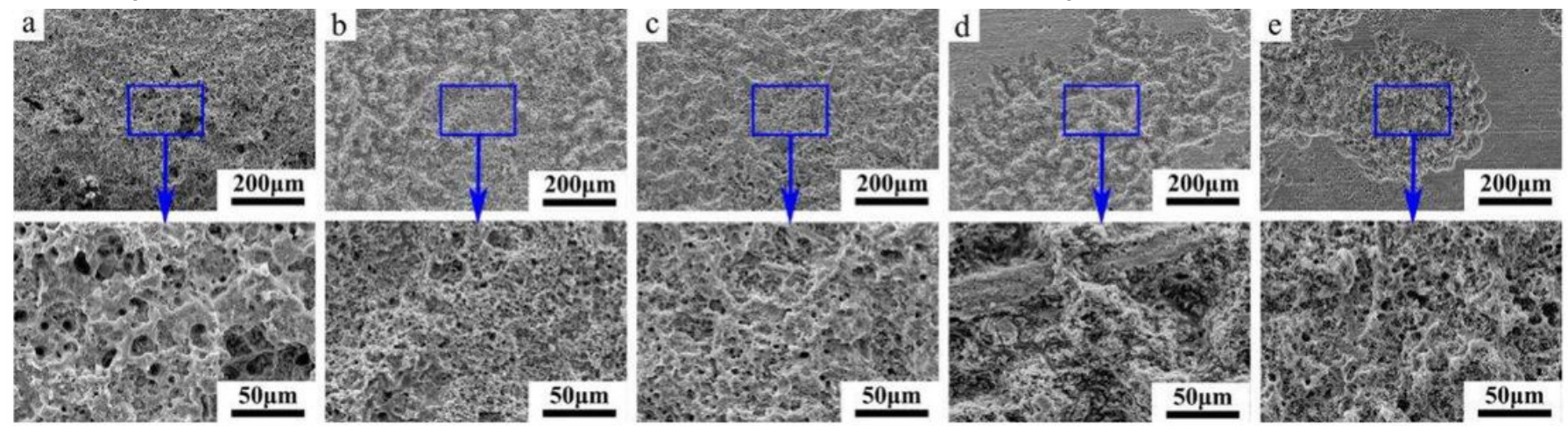

Figure 9

Corrosion morphology of different parameters (removal of corrosion products): (a) BM, (b) $800 \mathrm{rpm}-60$ $\mathrm{mm} / \mathrm{min}$, (c) $1000 \mathrm{rpm}-60 \mathrm{~mm} / \mathrm{min}$, (d) $1200 \mathrm{rpm}-60 \mathrm{~mm} / \mathrm{min}$, (e) $1200 \mathrm{rpm}-80 \mathrm{~mm} / \mathrm{min}$. (The figure 
below is an enlarged view of the figure above.)
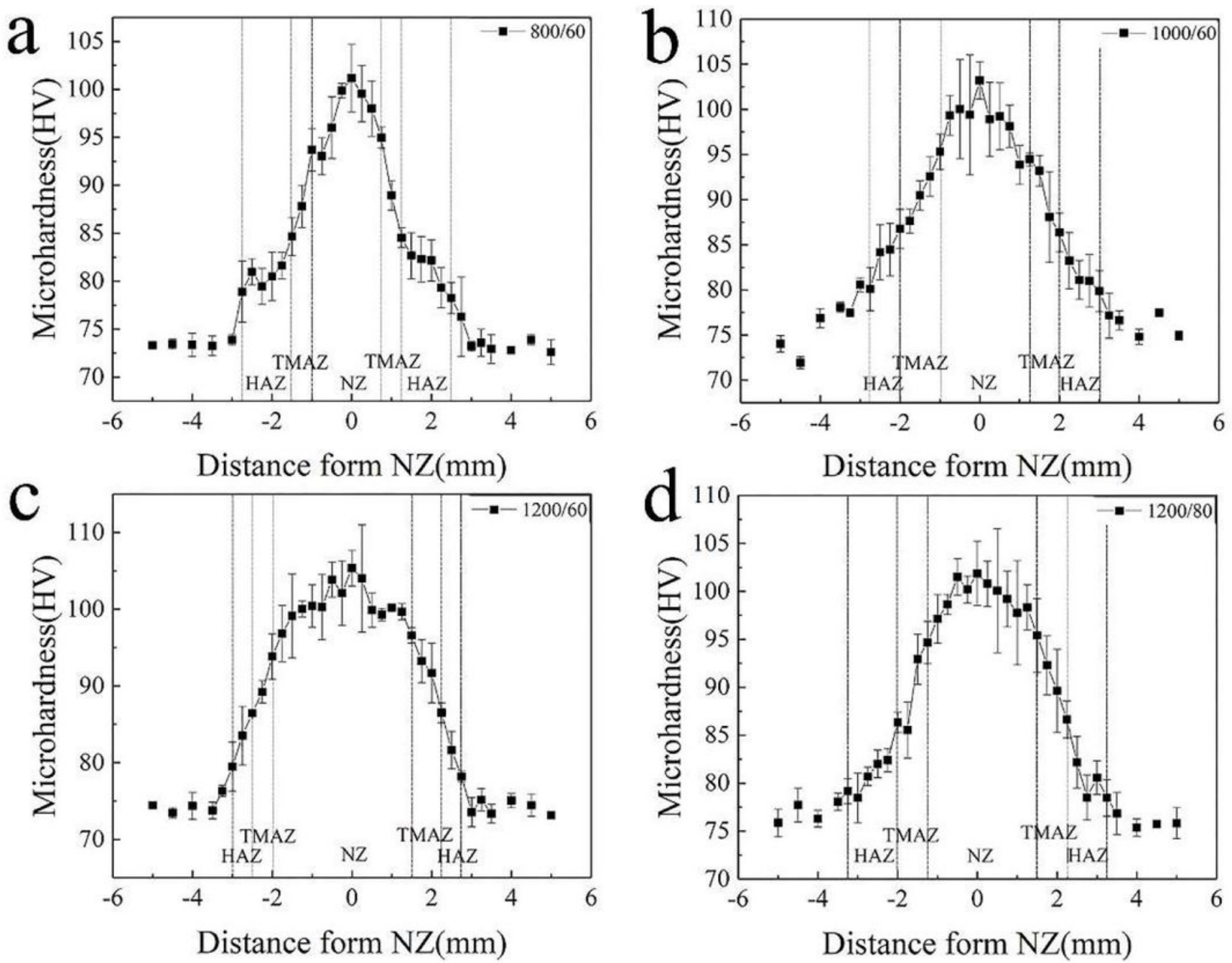

Figure 10

Microhardness distribution of four welds under different parameters: (a) $800 \mathrm{rpm}-60 \mathrm{~mm} / \mathrm{min}$, (b) 1000 rpm-60 mm/min, (c) $1200 \mathrm{rpm}-60 \mathrm{~mm} / \mathrm{min}$, (d) $1200 \mathrm{rpm}-80 \mathrm{~mm} / \mathrm{min}$.

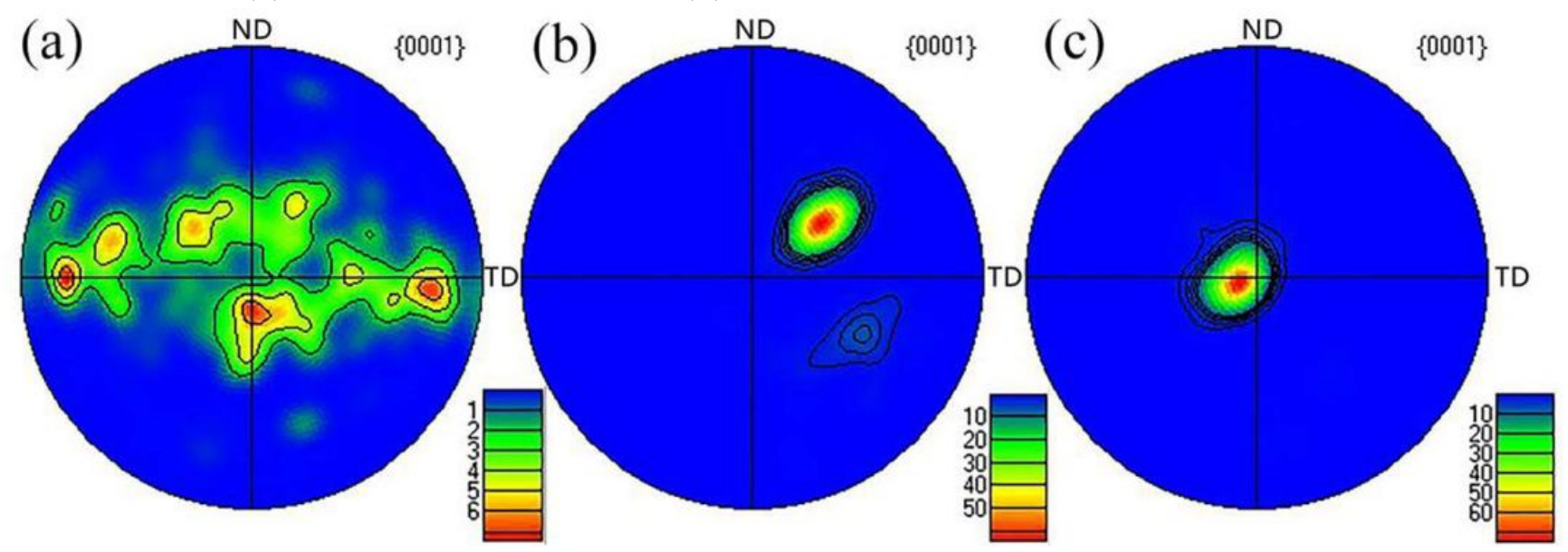


$\{0001\}$ pole figures of grain orientation: (a) BM, (b) TMAZ, (c) NZ.
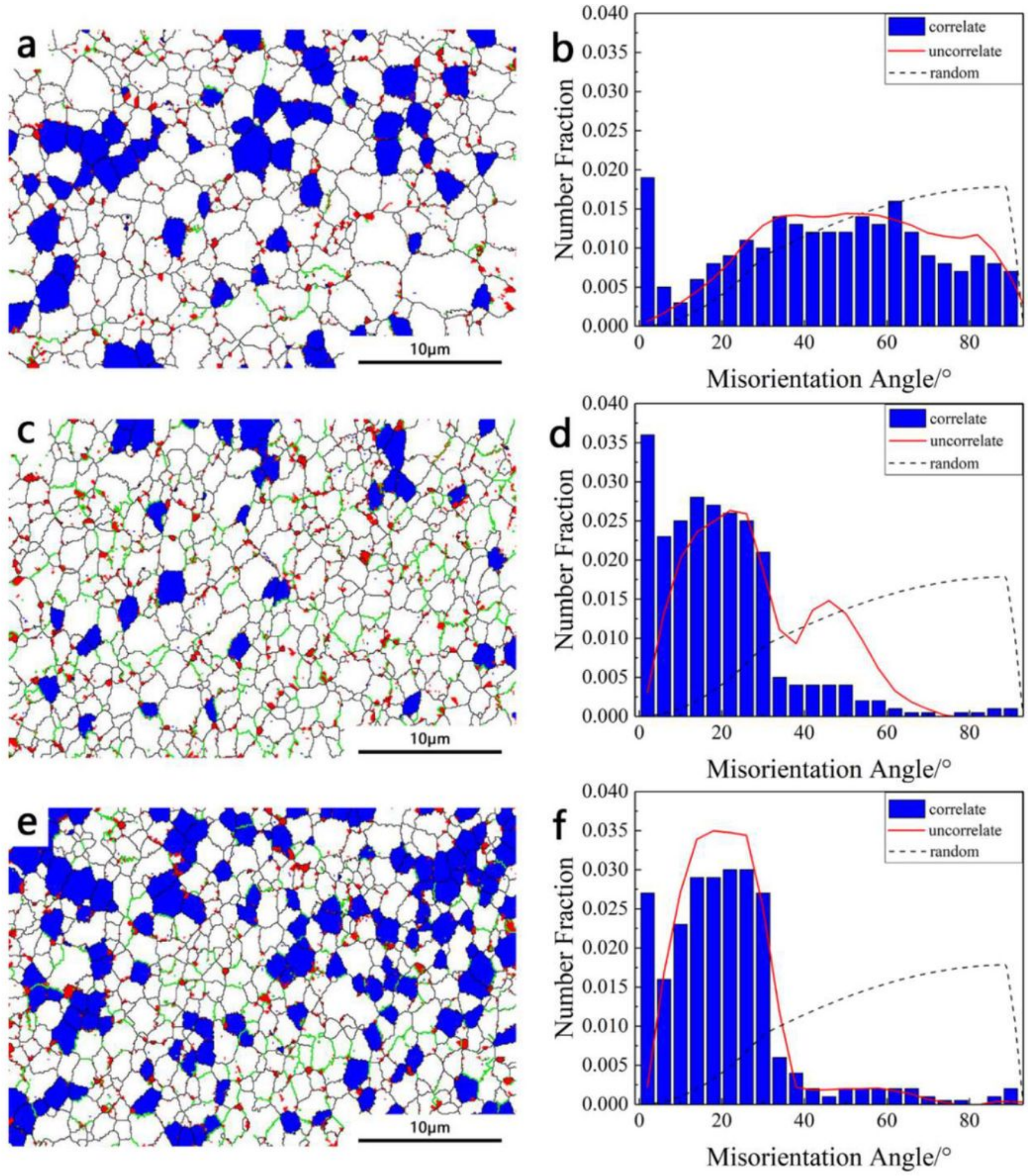

Figure 12

Misorientation distribution and grain boundary images of BM, TMAZ and NZ: (a) Grain boundary images of BM; (b) Misorientation-angle distributions of BM; (c) Grain boundary maps of TMAZ; (d) Misorientation-angle distributions of TMAZ; (e) Grain boundary maps of NZ; (f) Misorientation-angle distributions of NZ. 